\title{
Nine new species and new records of euryglossiform Scrapter Lepeletier \& Serville (Hymenoptera: Colletidae) from South Africa
}

\author{
Michael KUHLMANN ${ }^{1, *} \&$ Thyra FRIEHS ${ }^{2}$ \\ 1,2 Zoological Museum, University of Kiel, Hegewischstraße 3, D-24105 Kiel, Germany. \\ *Corresponding author: mkuhlmann@zoolmuseum.uni-kiel.de \\ 2Email: thyrafriehs@yahoo.de \\ ${ }^{1}$ urn:1sid:zoobank.org:author:B99AE0ED-FA89-4DFE-A658-1C8DF37F9FAB \\ ${ }^{2}$ urn:lsid:zoobank.org:author:CE708D50-8FB6-444B-90B2-4B696ADE74C9
}

\begin{abstract}
Nine new species of the South African endemic group of euryglossiform bees of the genus Scrapter Lepeletier \& Serville, 1828 are described, thus bringing the total number of species to 29 in this species-group: Scrapter avontuurensis Kuhlmann sp. nov. + , S. bokkeveldensis Kuhlmann sp. nov. + , S. fynbosensis Kuhlmann sp. nov. , S. hergi Kuhlmann sp. nov. O̊, S. keiskiensis Kuhlmann sp. nov. + , S. mellonholgeri Kuhlmann sp. nov. 워, S. nitens Kuhlmann sp. nov. ㅇ, S. oubergensis Kuhlmann sp. nov. + and $S$. willemstrydomi Kuhlmann sp. nov. $\delta$. The new replacement name $S$. punctulatus nom. nov. is proposed for $S$. punctatus Kuhlmann, 2014 which is a junior primary homonym of S. punctatus Lepeletier \& Audinet-Serville, 1825 (= Allodape punctata [Lepeletier \& Audinet-Serville, 1825]). Moreover, new records for already described taxa are presented and an updated key to all species of euryglossiform Scrapter is provided.
\end{abstract}

Key words. Scrapter, bees, South Africa, new species, taxonomy.

Kuhlmann M. \& Friehs T. 2020. Nine new species and new records of euryglossiform Scrapter Lepeletier \& Serville (Hymenoptera: Colletidae) from South Africa. European Journal of Taxonomy 647: 1-33.

https://doi.org/10.5852/ejt.2020.647

\section{Introduction}

The bee genus Scrapter Lepeletier \& Serville, 1828 currently comprises 59 described species (Eardley 1996; Davies et al. 2005; Davies \& Brothers 2006; Kuhlmann 2014) and is largely endemic to southern Africa with its center of diversity in the Greater Cape Floristic Region (GCFR) (Kuhlmann 2005, 2009). A single species was recorded from Kenya (Davies et al. 2005). In sub-Saharan Africa, Scrapter can easily be identified as it is the only abundantly hairy colletid bee genus with two submarginal cells in the forewing (Michener 2007).

Scrapter is morphologically highly diverse (Davies \& Brothers 2006) and based on this diversity Eardley (1996) defined a number of species-groups. The smallest species (ranging from 3.5 to $6.6 \mathrm{~mm}$ ) resemble the Australian Euryglossinae in their body shape, sparse pilosity, surface sculpture and narrow groove- 
like facial fovea. For them, Kuhlmann (2014) described a new species-group, namely the euryglossiform Scrapter. They possibly are the most basal species within Scrapter that as a genus is the sister-group of the Australian Euryglossinae (Almeida \& Danforth 2009; Almeida et al. 2012; Kayaalp et al. 2017). The 20 species of this group are predominantly black, with some species having partly yellow legs. They are characterized by a) a sulcus-like facial fovea with an invisible bottom as in Hylaeus Fabricius, $1793, b)$ a basitibial plate of the female with simple marginal carinae, c) body small, without metasomal hair bands in females and most males, and d) membraneous apicolateral lobes on male S7 (sometimes reduced) (Kuhlmann 2014).

In the last five years since the first revision of euryglossiform Scrapter (Kuhlmann 2014), several new species have been discovered in the GCFR. In the same period of time, the GCFR suffered from severe drought conditions culminating in the Cape Town water crisis in 2017-18. Due to significantly reduced flower availability, particularly in Namaqualand, drought can have detrimental effects on bee populations (Mayer \& Kuhlmann 2004) including local extinction as one of us (MK) observed during regular fieldwork since 2014. Thus, this paper is also a contribution to documenting and making available taxonomic information on the unique and rich endemic bee fauna in a region particularly vulnerable to and affected by climate change (Kuhlmann et al. 2012).

This publication provides diagnoses and descriptions of nine new species of euryglossiform Scrapter collected in the GCFR in western South Africa, accompanied by illustrations and updated identification keys to all 29 species. For several species, new distributional records are given.

\section{Material and methods}

For morphology the terminology of Michener (2007) was used, whereas Harris (1979) was followed for the description of the surface sculpture. Puncture density is characterized by the relationship between puncture diameter (d) and the space between these punctures (i). Body length was measured from the vertex to the apex of the body. Images were taken with a Keyence VHX-5000 Digital Microscope.

\section{Abbreviations used for morphological structures:}

$\mathrm{S}=$ metasomal sternum

$\mathrm{T}=$ metasomal tergum

\section{Institutional acronyms for collections:}

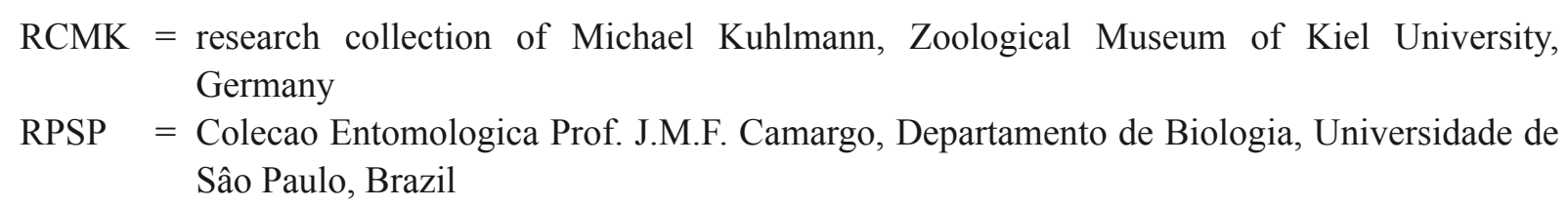

\section{The following abbreviations for collectors:}
$\mathrm{EA}=\mathrm{E}$. Almeida
$\mathrm{MK}=\mathrm{M}$. Kuhlmann
$\mathrm{KT}=\mathrm{K}$. Timmermann

\section{Results}

\section{Descriptions of new species of euryglossiform Scrapter}

The relationships of the new species are not known, so they are listed in alphabetical order. 


\author{
Class Insecta Linnaeus, 1758 \\ Order Hymenoptera Linnaeus, 1758 \\ Superfamily Apoidea Latreille, 1802 \\ Epifamily Anthophila Latreille, 1804 \\ Family Colletidae Lepeletier, 1841 \\ Subfamily Scraptrinae Ascher \& Engel, 2005 \\ Genus Scrapter Lepeletier \& Serville, 1828
}

Scrapter avontuurensis Kuhlmann sp. nov.

urn:lsid:zoobank.org:act:181B0BB4-BE81-41D8-864B-1B2E9729A765

Fig. 1

\title{
Diagnosis
}

The female of $S$. avontuurensis Kuhlmann sp. nov. can be separated from all other species of this group by the combination of the following characters: head distinctly broader than long; supraclypeal area and clypeus relatively sparsely and coarsely punctate, only partly superficially sculptured and slightly matt (Fig. 1B); scutum densely but relatively coarsely punctate (Fig. 1C); propodeum basally broadly and distinctly carinate (Fig. 1D); stigma brown; apical margins of metasomal terga broadly translucent dark reddish-brown; terga between punctures superficially sculptured and slightly matt (Fig. 1E). The male is unknown.

\section{Etymology}

Named after the Avontuur Nature Reserve where this species was discovered.

Material examined (1 specimen)

Holotype

SOUTH AFRICA • + ; $12 \mathrm{~km} \mathrm{NW}$ of Nieuwoudtville, Farm Avontuur, Fynbos; $31^{\circ} 16^{\prime} 18^{\prime \prime} \mathrm{S}, 19^{\circ} 02^{\prime} 55^{\prime \prime} \mathrm{E}$; alt. 770 m a.s.1.; 25 Sep. 2014; MK leg.; RCMK.

\section{Description}

\section{Female}

BODY LENGTH. $5.3 \mathrm{~mm}$.

HEAD. Head slightly wider than long. Integument black, except part of mandibles dark reddish-brown. Face sparsely covered with long, greyish, erect hair (Fig. 1B). Clypeus strongly convex with coarse and medially relatively dense $(i=1-2 \mathrm{~d})$ punctation and sparser $(i=2-4 \mathrm{~d})$ punctation at margins; surface between punctures superficially sculptured and matt (Fig. 1B). Malar area medially narrow, almost linear. Antenna dorsally blackish-brown, ventrally yellowish-brown.

Mesosoma. Integument black, tegula dark reddish-brown. Mesoscutal disc between punctures reticulate and matt; disc relatively densely ( $\mathrm{i}=1-2 \mathrm{~d}$ ) but coarsely punctate (Fig. 1C). Metanotum slightly shorter than basal area of propodeum, apically with distinct narrow carinate depression (Fig. 1D). Propodeum basally finely but broadly carinate (Fig. 1D). Mesoscutum, scutellum, metanotum, mesepisternum and propodeum sparsely covered with short, greyish, erect hair (Fig. 1A).

Wings. Yellowish-brown; wing venation and stigma brown.

LEGS. Integument black; fore tibia basally with small yellow spot. Vestiture greyish-white; scopa greyishwhite, dorsally brownish. 
Metasoma. Integument black, apical margin of first terga narrowly, margins of following terga broadly translucent dark reddish-brown (Fig. 1E). Disc of T1 and T2 glabrous; following terga with very short but increasingly more and longer hair; apical tergal hair bands missing on all terga (Fig. 1E). Prepygidial and pygidial fimbriae sparse, yellowish-brown. T1-T3 finely and densely $(\mathrm{i}=\mathrm{d})$ punctate, between punctures superficially sculptured and slightly matt; T4 matt; T2-T4 with polished to superficially sculptured, but shiny apical tergal depression (Fig. 1E).

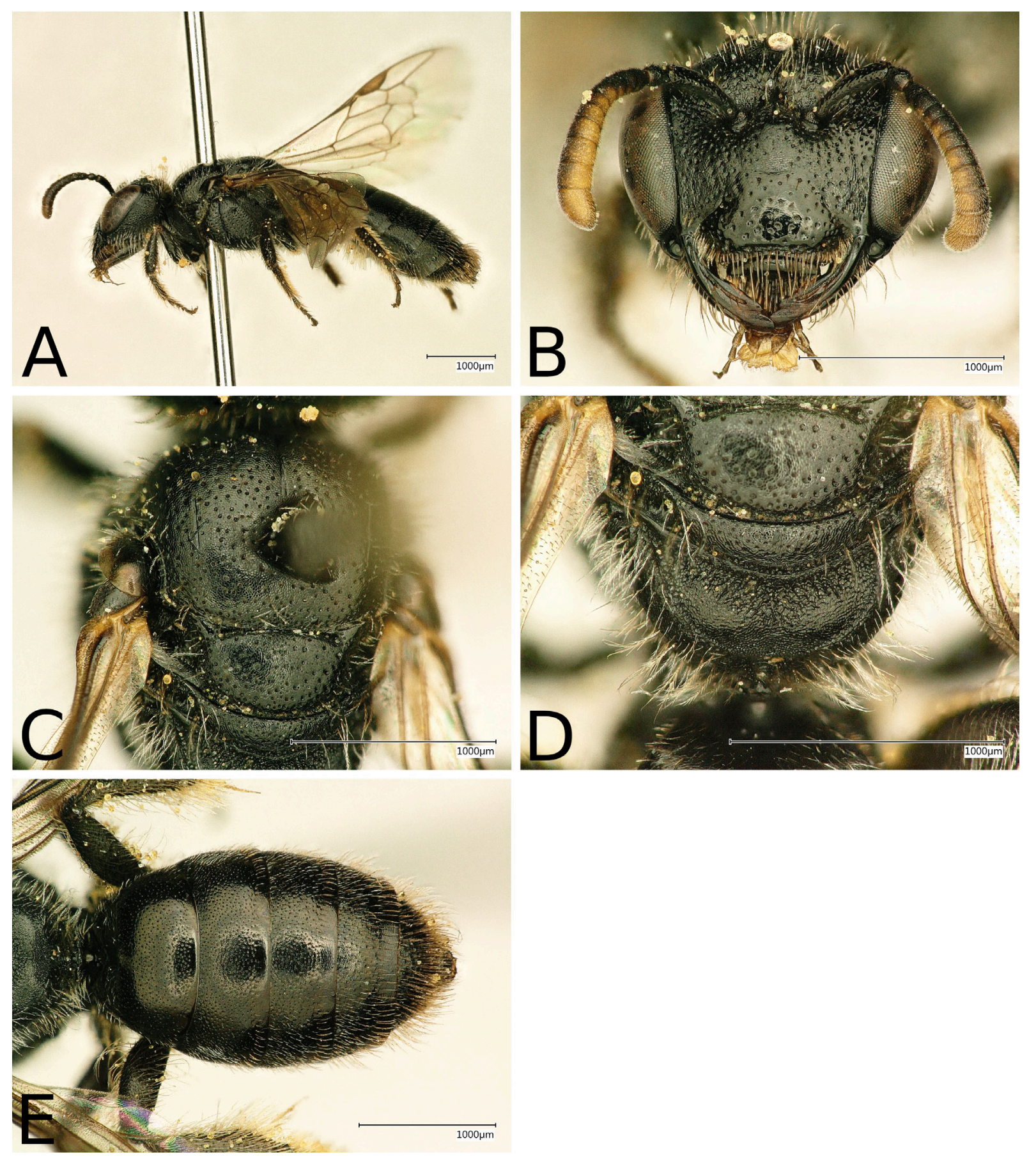

Fig. 1. Scrapter avontuurensis Kuhlmann sp. nov., $q$, holotype (RCMK). A. Lateral view. B. Head. C. Scutum and scutellum (dorsal view). D. Metanotum and propodeum (dorsal view). E. Metasoma (dorsal view). 


\section{Male \\ Unknown.}

\section{Distribution}

Only known from the type locality north of Nieuwoudtville.

\section{Floral hosts}

Brassicaceae: Heliophila spec.

\section{Seasonal activity}

September.

Scrapter bokkeveldensis Kuhlmann sp. nov. urn:1sid:zoobank.org:act:E525ECD2-A2BB-4493-93B5-5436A01A6E05

Fig. 2

\section{Diagnosis}

The female of S. bokkeveldensis Kuhlmann sp. nov. can be separated from all other species of this group by the combination of the following characters: supraclypeal area and clypeus superficially sculptured but shiny, sparsely and coarsely punctate (Fig. 2B); scutum relatively densely and coarsely punctate (Fig. 2C); propodeum only laterally with distinct but fine carination (Fig. 2D); stigma brown; apical margins of metasomal terga black; terga finely and densely punctate (Fig. 2E). The male is unknown.

\section{Etymology}

Named after the Bokkeveld Plateau that stretches along the escarpment north and south of Nieuwoudtville.

Material examined (1 specimen)

\section{Holotype}

SOUTH AFRICA • $\odot$; 12 km NW of Nieuwoudtville, Farm Avontuur, Fynbos; $31^{\circ} 16^{\prime} 18^{\prime \prime} \mathrm{S}, 1^{\circ} 02^{\prime} 55^{\prime \prime}$ E; alt. 770 m a.s.1.; 9 Sep. 2018; MK leg; RCMK.

\section{Description}

\section{Female}

Body Length. $4.3 \mathrm{~mm}$.

HEAD. Head slightly wider than long. Integument black, except part of mandibles dark reddish-brown. Face sparsely covered with long, greyish, erect hair (Fig. 2B). Clypeus slightly convex with coarse and relatively sparse $(\mathrm{i}=1-3 \mathrm{~d})$ punctation; surface between punctures superficially sculptured but shiny (Fig. 2B). Malar area medially narrow, almost linear. Antenna dorsally blackish-brown, ventrally yellowish-brown.

Mesosoma. Integument black, tegula dark reddish-brown. Mesoscutal disc between punctures superficially shagreened and slightly matt; disc relatively densely ( $=1-2 \mathrm{~d}$ ) but relatively coarsely punctate (Fig. 2C). Metanotum about as long as basal area of propodeum, apically with distinct narrow carinate depression (Fig. 2D). Propodeum basally only laterally distinctly but relatively finely carinate (Fig. 2D). Mesoscutum, scutellum, metanotum, mesepisternum and propodeum sparsely covered with short, greyish, erect hair (Fig. 2A). 
Wings. Brownish; wing venation and stigma brown.

LEGS. Integument black. Vestiture greyish to yellowish-brown; scopa greyish-white, dorsally brownish.

METASOMA. Integument black, apical margins of terga broadly black to translucent dark reddish-brown (Fig. 2E). Disc of T1-T2 without hair; following terga with very short but increasingly more and longer
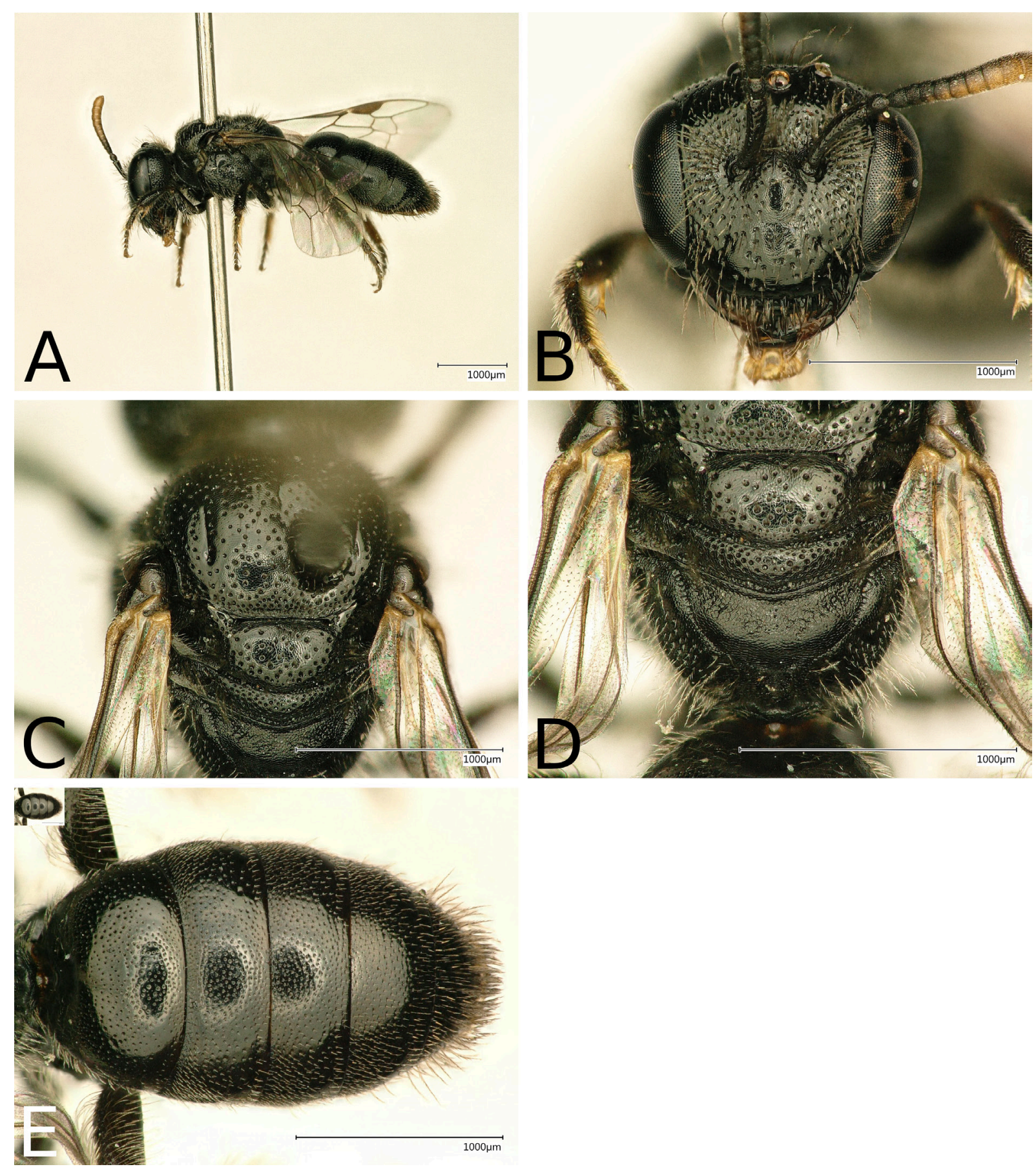

Fig. 2. Scrapter bokkeveldensis Kuhlmann sp. nov.,, , holotype (RCMK). A. Lateral view. B. Head. C. Scutum and scutellum (dorsal view). D. Metanotum and propodeum (dorsal view). E. Metasoma (dorsal view). 
hair; apical tergal hair bands missing on all terga (Fig. 2E). Prepygidial and pygidial fimbriae relatively short, brownish. T1-T4 densely $(\mathrm{i}=0.5-1 \mathrm{~d})$ and relatively coarsely punctate, $\mathrm{T} 1-\mathrm{T} 2$ between punctures smooth and shiny, T3-T4 between punctures superficially reticulate but shiny; T2-T4 with polished and shiny apical tergal depression (Fig. 2E).

\section{Male}

Unknown.

\section{Distribution}

Only known from the type locality north of Nieuwoudtville.

\section{Floral hosts}

Brassicaceae: blue Heliophila spec.

\section{Seasonal activity}

September.

$$
\begin{gathered}
\text { Scrapter fynbosensis Kuhlmann sp. nov. } \\
\text { urn:lsid:zoobank.org:act:5C833926-5130-472D-8A0D-A2A832801F9A }
\end{gathered}
$$

Fig. 3

\section{Diagnosis}

The female of $S$. fynbosensis Kuhlmann sp. nov. can be separated from all other species of this group by the combination of the following characters: supraclypeal area and clypeus superficially sculptured but shiny (Fig. 3B); scutum between punctures reticulate and matt (Fig. 3C); foretibia dominantly blackish; stigma brown; apical margins of metasomal terga broadly translucent yellowish-brown; terga between punctures superficially sculptured and slightly matt (Fig. 3E). The male is unknown.

\section{Etymology}

Named after the Fynbos biome where this species was discovered.

Material examined (1 specimen)

\section{Holotype}

SOUTH AFRICA • ; N Cape, $15 \mathrm{~km} \mathrm{NW}$ of Nieuwoudtville, Farm Engelsepunt, Fynbos, Pf E1; $31^{\circ} 14^{\prime} 31^{\prime \prime} \mathrm{S}, 18^{\circ} 59^{\prime} 08^{\prime \prime}$ E; alt. 830 m a.s.1.; 23 Jul. 2003; KT leg; RCMK.

\section{Description}

\section{Female}

Body LENGTH. $5.2 \mathrm{~mm}$.

HEAD. Head slightly wider than long. Integument black, except part of mandibles dark reddish-brown. Face sparsely covered with long, greyish, erect hair (Fig. 3B). Clypeus almost flat with relatively dense (i $=1-2 \mathrm{~d}$ ) and shallow punctation; surface between punctures only partly sculptured and shiny (Fig. 3B). Malar area medially narrow, almost linear. Antenna dorsally blackish-brown, ventrally yellowishbrown.

Mesosoma. Integument black, tegula dark reddish-brown. Mesoscutal disc between punctures reticulate and matt; disc relatively densely $(\mathrm{i}=1-2 \mathrm{~d}$ ) and coarsely punctate (Fig. 3C). Metanotum about as 
long as basal area of propodeum, apically with broad carinate depression (Fig. 3D). Propodeum basally relatively finely carinate (Fig. 3D). Mesoscutum, scutellum, metanotum, mesepisternum and propodeum sparsely covered with short, greyish, erect hair (Fig. 3A).

WINGS. Yellowish-brown; wing venation and stigma brown.
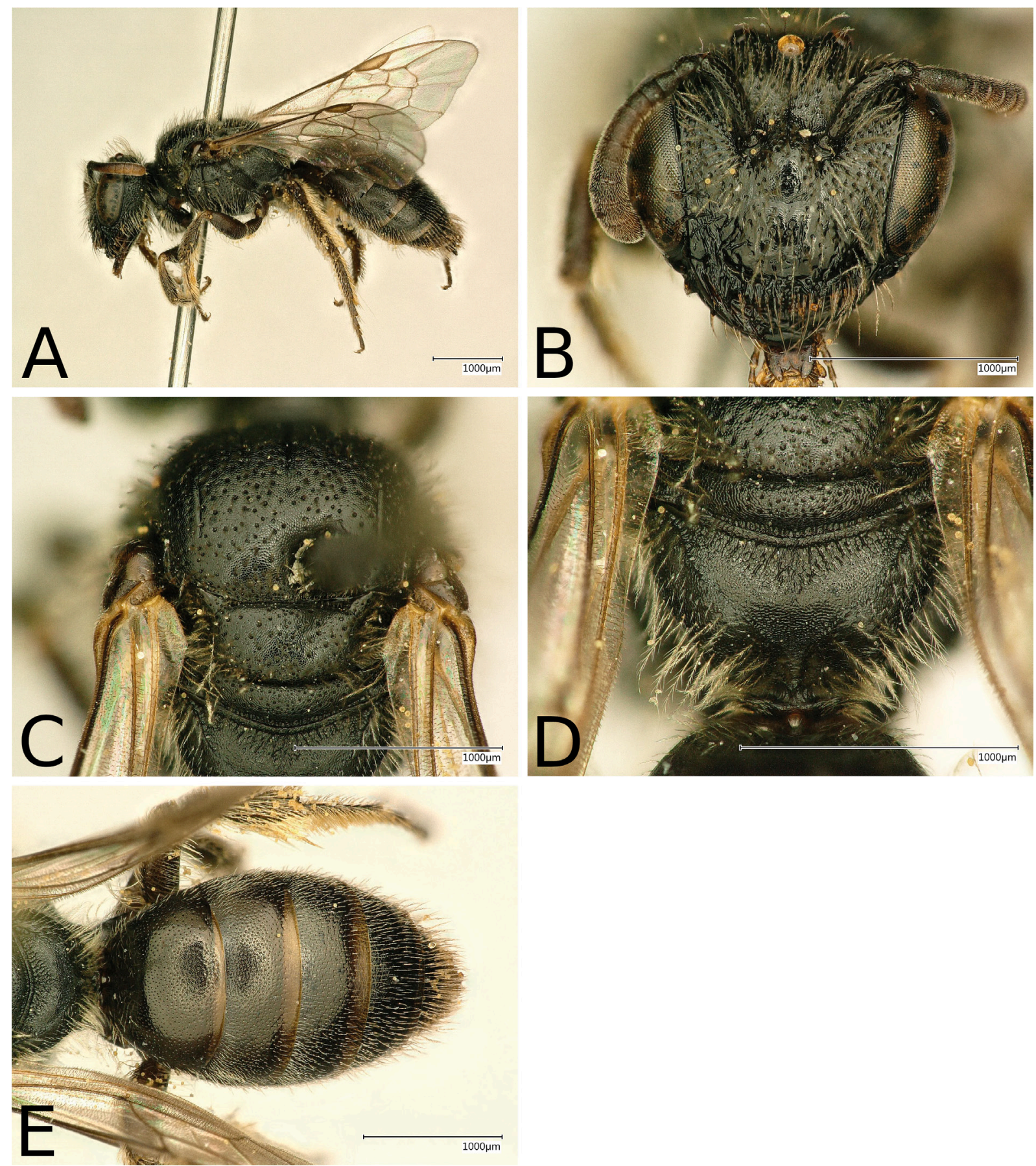

Fig. 3. Scrapter fynbosensis Kuhlmann sp. nov., + , holotype (RCMK). A. Lateral view. B. Head. C. Scutum and scutellum (dorsal view). D. Metanotum and propodeum (dorsal view). E. Metasoma (dorsal view). 
LEGS. Integument black; fore tibia anteriorly on basal half with small yellowish spot. Vestiture greyishwhite; scopa greyish-white, dorsally brownish.

Metasoma. Integument black to dark reddish-brown, apical margins of terga broadly translucent yellowish to reddish-brown (Fig. 3E). Disc of T1 without hair; following terga with very short but increasingly more and longer hair; apical tergal hair bands missing on all terga (Fig. 3E). Prepygidial and pygidial fimbriae yellowish-brown. Terga finely and densely $(\mathrm{i}=\mathrm{d})$ punctate, $\mathrm{T} 1-\mathrm{T} 3$ between punctures superficially sculptured and slightly matt; T4 matt; T2-T4 with polished to superficially sculptured, but shiny apical tergal depression (Fig. 3E).

\section{Male}

Unknown.

\section{Distribution}

Only known from the type locality north of Nieuwoudtville.

\section{Floral hosts}

Unknown.

\section{Seasonal activity}

July.

Scrapter hergi Kuhlmann sp. nov. urn:1sid:zoobank.org:act:144393B8-3241-4629-A8C5-BEA2E14DD09D

Fig. 4

\section{Diagnosis}

The male of $S$. hergi Kuhlmann sp. nov. can be separated from all other species of this group by the combination of the following characters: head distinctly longer than wide (Fig. 4E); antenna ventrally orange-brown (Fig. 4E); hind tibia apically broadened inside, forming a \pm right angle (Fig. 4G) and the shape of S7 (Fig. 4F). The female is unknown.

\section{Etymology}

The species is dedicated to Hergen ('Hergi') Erhardt, Edewecht (Germany) who joined and supported me (MK) in a couple of collecting trips; noun in apposition.

Material examined (1 specimen)

\section{Holotype}

SOUTH AFRICA - \; Roggeveld Mts, 2 km SE of Farm Allemansdam, burnt area; 31 $49^{\prime} 32^{\prime \prime}$ S, 1959'55" E; alt. 1290 m a.s.1.; 2 Sep. 2017; MK leg.; RCMK.

\section{Description}

\section{Female}

Unknown.

Male

BODY LENGTH. $5.8 \mathrm{~mm}$. 


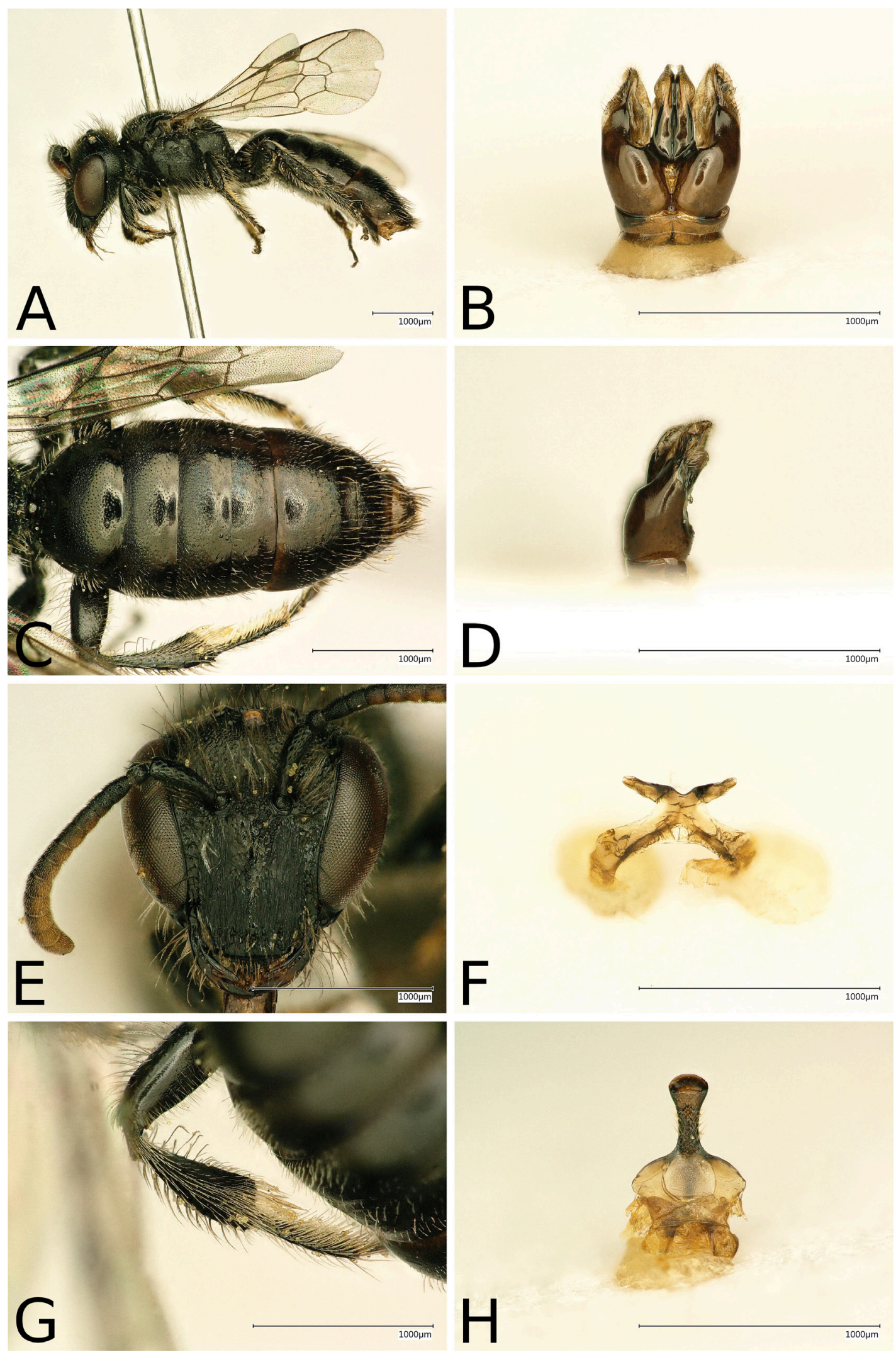

Fig. 4. Scrapter hergi Kuhlmann sp. nov., Ô, holotype (RCMK). A. Lateral view. B. Genitalia (dorsal view). C. Metasoma (dorsal view). D. Genitalia (lateral view). E. Head. F. S7 (dorsal view). G. Hind tibia. H. S8, apical end. 
HeAD. Head longer than wide. Integument black, except mandible partly dark reddish-brown. Face covered with long, greyish-white, erect hair. Malar area medially narrow, almost linear. Antenna dorsally dark brown, ventrally orange-brown (Fig. 4E).

Mesosoma. Integument black. Mesoscutal disc between punctures strongly reticulate and matt; disc finely, very shallowly and almost invisible, very sparsely $(i=3-5 d)$ punctate. Mesoscutum, scutellum, metanotum, mesepisternum and propodeum covered with long, greyish, erect hair (Fig. 4A).

WINGS. Slightly yellowish-brown; wing venation and stigma brown.

LEGS. Integument black to dark reddish-brown. Hind tibia inside apically broadened, forming a \pm right angle (Fig. 4G). Vestiture greyish-white.

Metasoma. Integument black, apical margins of terga partly narrowly translucent dark reddish-brown (Fig. 4C). Discs of T1-T2 without hair, following terga with sparse and short but successively more and longer hair; apical tergal hair bands missing on all terga (Fig. 4C). T1-T3 densely ( $i=0.5-1 \mathrm{~d}$ ) but finely punctate, T4 and following terga almost invisible very finely and superficially punctate; between punctures superficially sculptured and shiny to slightly matt; T2-T4 with narrow, superficially sculptured but shiny apical tergal depression (Fig. 4C). S3 and particularly S4-S5 with sparse, long apical hair fringes.

Terminalia. Genitalia (Fig. 4B, D), S7 (Fig. 4F) and terminal plate of S8 (Fig. 4H) as illustrated.

\section{Distribution}

Only known from the type locality in the northern part of the Roggeveld Mts south of Calvinia.

\section{Floral hosts}

Unknown.

\section{Seasonal activity}

September.

Scrapter keiskiensis Kuhlmann sp. nov. urn:1sid:zoobank.org:act:C74E162D-8699-47CB-837C-B3E5A638CD6C

Fig. 5

\section{Diagnosis}

The female of S. keiskiensis Kuhlmann sp. nov. can be separated from all other species of this group by the combination of the following characters: head distinctly broader than long; supraclypeal area and clypeus sculptured and matt, densely and distinctly punctate (Fig. 5B); scutum densely and relatively coarsely punctate (Fig. 5C); propodeum indistinctly and shallowly carinate (Fig. 5D); stigma brown; apical margins of metasomal terga black or only slightly translucent dark reddish-brown; terga between punctures superficially sculptured and slightly matt (Fig. 5E). The male is unknown.

\section{Etymology}

Named after the Keiski Mts south of Calvinia where this species was first collected. 
Material examined (2 specimens)

\section{Holotype}

SOUTH AFRICA • + ; Roggeveld Mts, 1,5 km S of Farm Allemansdam, Renosterveld; 31 $49^{\prime} 25^{\prime \prime} \mathrm{S}$, 1959'38" E; alt. 1285 m a.s.1.; 11 Sep. 2018; MK leg; RCMK.

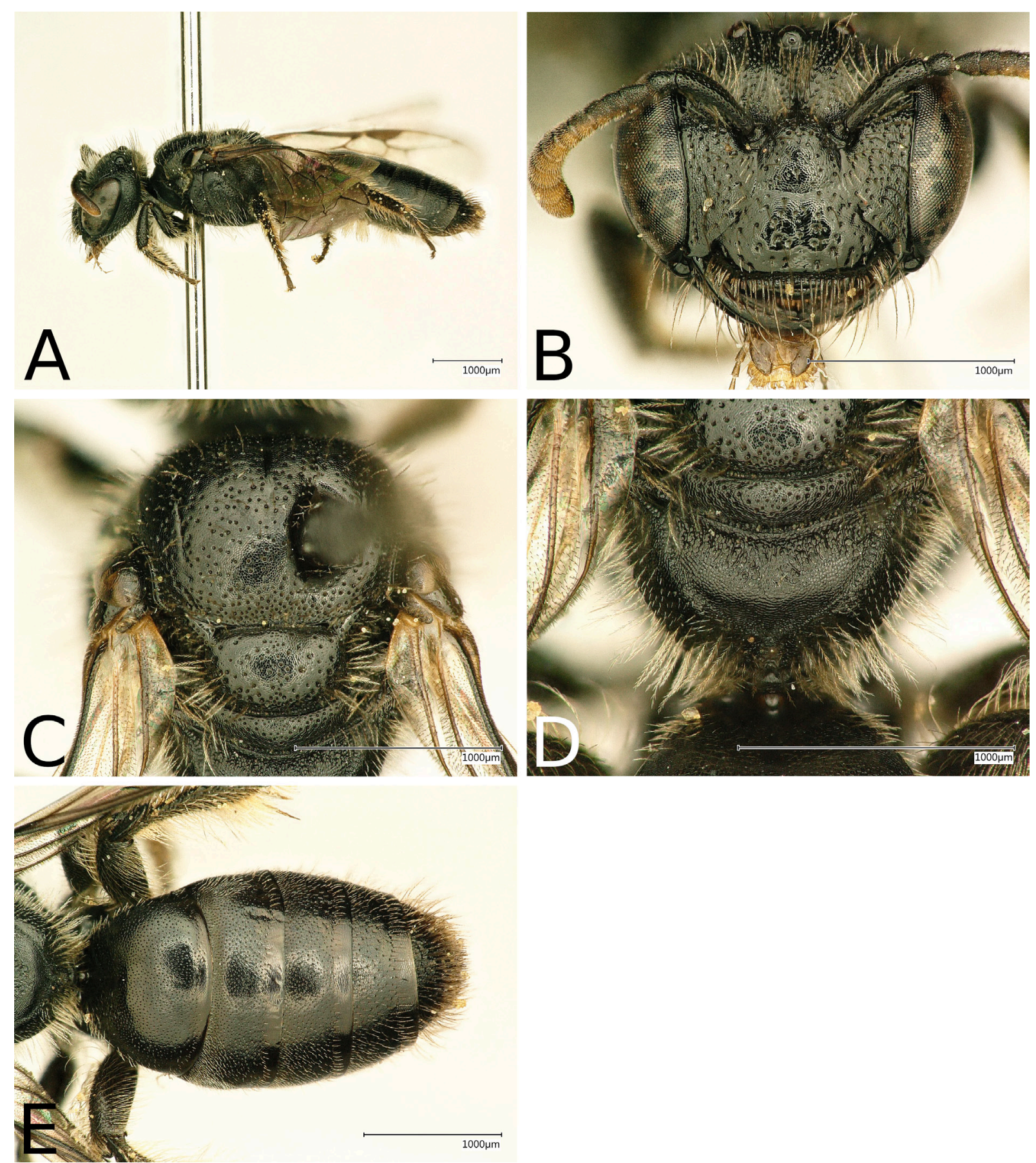

Fig. 5. Scrapter keiskiensis Kuhlmann sp. nov., + , holotype (RCMK). A. Lateral view. B. Head. C. Scutum and scutellum (dorsal view). D. Metanotum and propodeum (dorsal view). E. Metasoma (dorsal view). 


\section{Paratype}

SOUTH AFRICA • 1 q; Keiski Mts, 3 km E of Farm M’Vera, shale; 3145'29" S, 1954'13" E; alt. 1190 m a.s.1.; 13 Sep. 2016; MK leg; RCMK.

\section{Description}

\section{Female}

Body LeNGTH. $5.4 \mathrm{~mm}$.

HEAD. Head distinctly wider than long. Integument black, except part of mandibles dark reddish-brown. Face sparsely covered with long, greyish, erect hair (Fig. 5B). Clypeus slightly convex with dense ( $\mathrm{i}=$ d) punctation, apically finer, basally coarser; surface between punctures sculptured and matt (Fig. 5B). Malar area medially narrow, almost linear. Antenna dorsally blackish-brown, ventrally yellowishbrown.

Mesosoma. Integument black. Mesoscutal disc between punctures reticulate and matt; disc densely $(\mathrm{i}=0.5-1 \mathrm{~d})$ and relatively finely punctate (Fig. 5C). Metanotum slightly shorter than basal area of propodeum, apically with narrow carinate depression (Fig. 5D). Propodeum basally distinct but very finely carinate (Fig. 5D). Mesoscutum, scutellum, metanotum, mesepisternum and propodeum sparsely covered with short, greyish, erect hair (Fig. 5A).

WINGS. Brownish; wing venation and stigma brown.

LEGS. Integument black. Vestiture greyish to yellowish; scopa greyish-white, dorsally brownish.

Metasoma. Integument black, apical margins on first terga narrow, on other terga broadly black to translucent dark reddish-brown (Fig. 5E). Disc of T1-T2 without hair; following terga with very short but increasingly more and longer hair; apical tergal hair bands missing on all terga (Fig. 5E). Prepygidial and pygidial fimbriae relatively short, yellowish-brown. T1-T4 finely and densely ( $\mathrm{i}=0.5-1 \mathrm{~d})$ punctate, between punctures superficially sculptured and slightly matt; T2-T4 with superficially reticulate but shiny apical tergal depression (Fig. 5E).

\section{Male}

Unknown.

\section{Distribution}

Only known from the northern extension of the Roggeveld Mts and the adjacent Keiski Mts.

\section{Floral hosts}

Aizoaceae: Galenia sarcophylla.

\section{Seasonal activity}

September. 


\section{Scrapter mellonholgeri Kuhlmann sp. nov. urn:Isid:zoobank.org:act:F5E08BBE-DDEE-41DF-9369-DBA7FC851046}

Figs $6-7$

\section{Diagnosis}

The female of S. mellonholgeri Kuhlmann sp. nov. can be separated from all other species of this group by the combination of the following characters: head distinctly broader than long; supraclypeal area and clypeus superficially sculptured and slightly matt, coarsely and densely to sparsely punctate (Fig. 6B); scutum mostly relatively sparse and slightly coarsely punctate (Fig. 6C-D); propodeum basally just slightly (Fig. 6E-F); stigma brown; apical margins of metasomal terga slightly translucent dark reddishbrown; terga densely and finely punctate (Fig. 6G). The male is characterized by an unmodified antenna; coarsely and densely punctate scutum; finely and densely punctate metasomal terga (Fig. 7C); hind tibia apically broadened inside, forming a spine (Fig. 7E); third hind tarsus unmodified (Fig. 7G) and the shape of S7 (Fig. 7F).

\section{Etymology}

This species is dedicated to my (MK) friend (High Elvish [Sindarin]: mellon; noun in apposition) Holger Heinrich Dathe, expert in bees of the genus Hylaeus and former director of the Senckenberg German Entomological Institute, Müncheberg, in recognition of his ground breaking contributions to Afrotropical taxonomy of Hylaeus.

Material examined (44 specimens)

\section{Holotype}

SOUTH AFRICA - ô; Roggeveld Mts, $2 \mathrm{~km}$ SE of Farm Allemansdam, burnt area; 31 ${ }^{\circ} 49^{\prime} 32^{\prime \prime}$ S, 1959'55" E; alt. 1290 m a.s.1.; 2 Sep. 2017; MK leg.; RCMK.

\section{Paratypes}

SOUTH AFRICA - 2 qo; Kamiesberg Mts, $5 \mathrm{~km} \mathrm{SE}$ of Leliefontein, road side; alt. $30^{\circ} 20^{\prime} 09^{\prime \prime} \mathrm{S}$, $18^{\circ} 06^{\prime 2} 24^{\prime \prime} \mathrm{E}$; $1400 \mathrm{~m}$ a.s.l.; 7 Sep. 2016; MK leg.; RCMK • 7 o $\circ$; same collection data as for preceding;

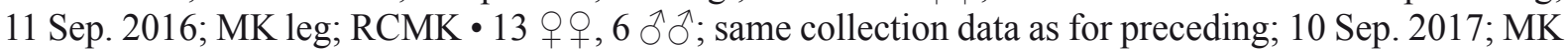

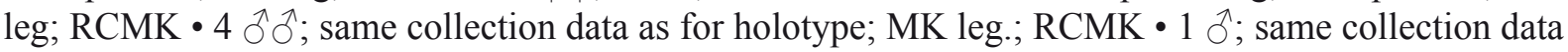
as for holotype; 24 Aug. 2018; MK leg.; RCMK • 1 ठ ; same collection data as for holotype; 29 Aug. 2018; MK leg.; RCMK • 1 क; 8 km WNW of Leliefontein, Fynbos, road side; $30^{\circ} 15^{\prime} 58^{\prime \prime}$ S, $18^{\circ} 03^{\prime} 17^{\prime \prime} \mathrm{E}$; alt. $1190 \mathrm{~m}$ a.s.1.; 10 Sep. 2017; MK leg.; RCMK • 8 q $q$; same collection data as for preceding; 14 Sep. 2017; MK leg.; RCMK.

\section{Description}

\section{Female}

Body LENGTH. 4.4-5.3 mm.

HEAD. Head slightly wider than long. Integument black, except part of mandibles dark reddish-brown. Face sparsely covered with long, greyish, erect hair (Fig. 6B). Clypeus convex with relatively coarse but dense $(\mathrm{i}=0.5-1 \mathrm{~d})$ punctation; surface between punctures superficially reticulate and slightly matt (Fig. 6B). Malar area medially narrow, almost linear. Antenna dorsally blackish-brown, ventrally yellowish-brown.

Mesosoma. Integument black, tegula reddish-brown. Mesoscutal disc between punctures to a variable degree reticulate and slightly matt; disc relatively sparsely $(i=2-3 \mathrm{~d})$ and relatively finely to slightly coarsely punctate (Fig. 6D); sometimes disc shinier and with denser $(i=1 \mathrm{~d})$ punctation (Fig. 6C). Metanotum about as long as basal area of propodeum, apically with narrow carinate depression (Fig. 6E-F). Propodeum basally indistinctly and very finely carinate (Fig. 6F), sometimes only laterally 

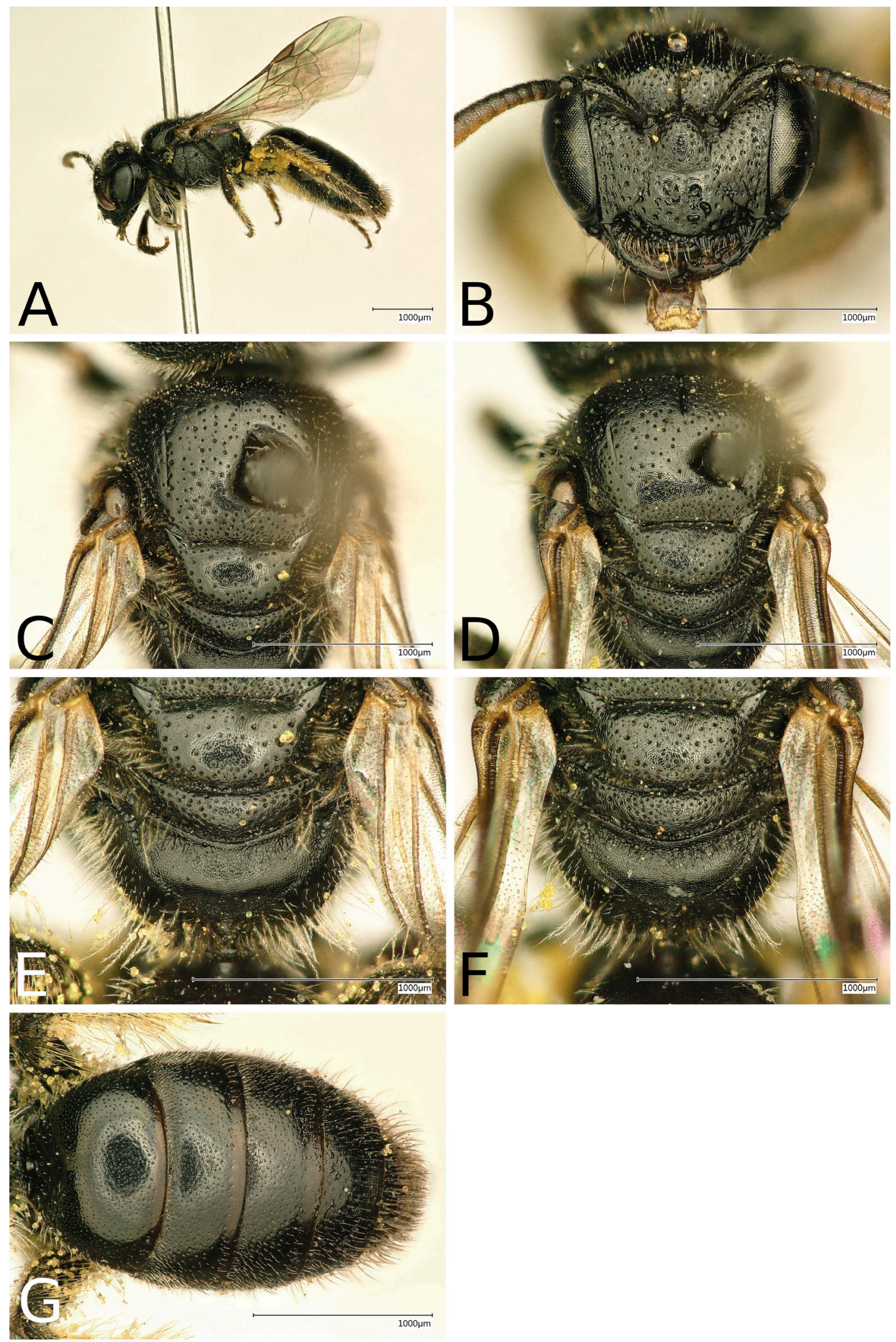

Fig. 6. Scrapter mellonholgeri Kuhlmann sp. nov.,, , paratype (RCMK). A. Lateral view. B. Head. C-D. Scutum and scutellum (dorsal view). Variation of sculpture. E-F. Metanotum and propodeum (dorsal view). Variation of sculpture. G. Metasoma (dorsal view). 
carinate (Fig. 6E). Mesoscutum, scutellum, metanotum, mesepisternum and propodeum sparsely covered with short, greyish, erect hair (Fig. 6A).

Wings. Brownish; wing venation and stigma brown.

LEGS. Integument black. Vestiture greyish-white; scopa greyish-white, dorsally brownish.

Metasoma. Integument black, apical margins of terga narrowly black to translucent dark reddish-brown (Fig. 6G). Disc of T1-T2 glabrous; following terga with very short but increasingly more and longer hair; T3 basally with a very narrow and sparse band of very fine, short, erect hair; apical tergal hair bands missing on all terga (Fig. 6G). Prepygidial and pygidial fimbriae relatively short, greyish-brown. $\mathrm{T} 1$ finely and relatively densely ( $\mathrm{i}=1-1.5 \mathrm{~d}$ ) punctate, between punctures superficially sculptured and slightly matt; following terga more matt; $\mathrm{T} 2-\mathrm{T} 4$ with superficially sculptured and slightly matt apical tergal depression (Fig. 6G).

\section{Male}

Body LENGTH. 4.6-5.5 mm.

HEAD. Head slightly wider than long. Integument black, except mandible partly dark reddish-brown. Face densely covered with long, greyish-white, erect hair. Malar area medially narrow, almost linear. Antenna dorsally dark brown, ventrally yellowish-brown except last three flagellar segments completely or largely brown.

Mesosoma. Integument black. Mesoscutal disc between punctures reticulate and slightly matt to matt; disc sparsely $(\mathrm{i}=1.5-3 \mathrm{~d})$ and coarsely punctate. Mesoscutum, scutellum, metanotum, mesepisternum and propodeum sparsely covered with long, greyish, erect hair (Fig. 7A).

WINGs. Slightly yellowish-brown; wing venation and stigma brown.

LEGS. Integument black, fore tibia anteriorly dominantly yellowish-brown. Hind tibia inside apically broadened, with a spine (Fig. 7E). Hind basitarsus medially slightly broadened (Fig. 7G). Vestiture greyish-white.

MeтAsомa. Integument black to dark reddish-brown, apical margins of terga partly narrowly translucent dark reddish-brown (Fig. 7C). Discs of T1-T2 without hair, following terga with short but increasingly more and longer hair; T3 and T4 basally with a very narrow and sparse band of short greyish, erect hair; apical tergal hair bands missing on all terga (Fig. 7C). T1 finely, following terga relatively coarsely but densely $(\mathrm{i}=0.5-1 \mathrm{~d})$ punctate; superficially reticulate and slightly matt; $\mathrm{T} 2-\mathrm{T} 4$ with narrow, superficially sculptured but shiny apical tergal depression (Fig. 7C). S3 and particularly S4-S5 with sparse, long apical hair fringes.

Terminalia. Genitalia (Fig. 7B, D), S7 (Fig. 7F) and terminal plate of S8 (Fig. 7H) as illustrated.

\section{Distribution}

Recorded from the northern part of the Roggeveld Mts and the Kamisberg Mts.

\section{Floral hosts}

Brassicaceae: white Heliophila spec.

\section{Seasonal activity}

August-September. 

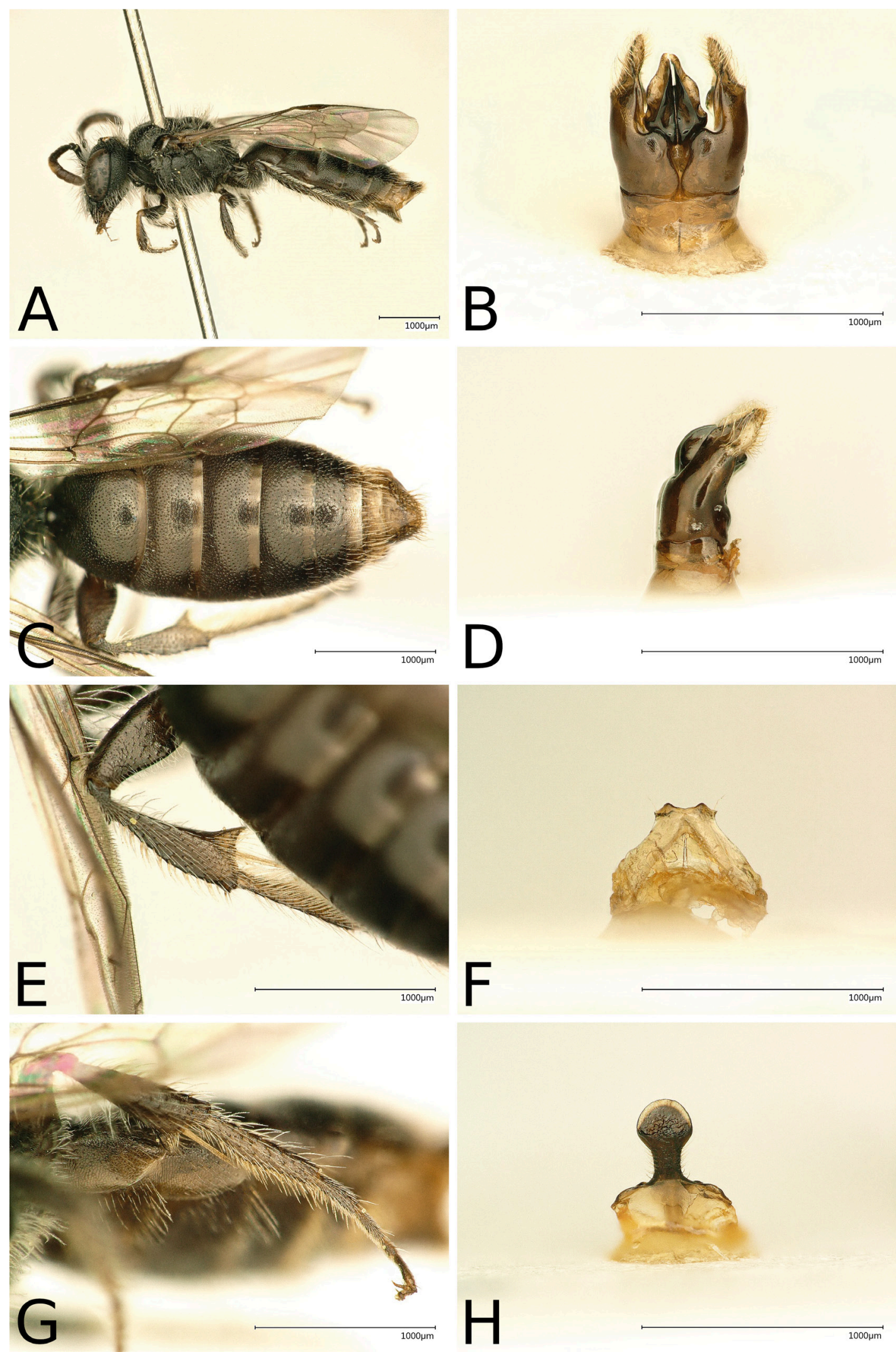

Fig. 7. Scrapter mellonholgeri Kuhlmann sp. nov., ổ, holotype (RCMK). A. Lateral view. B. Genitalia (dorsal view). C. Metasoma (dorsal view). D. Genitalia (lateral view). E. Hind tibia. F. S7 (dorsal view). G. Hind basitarsus. H. S8, apical end. 
Scrapter nitens Kuhlmann sp. nov.

urn:1sid:zoobank.org:act:46A356D8-8A3F-4806-BB16-6ACEBEFD7754

Fig. 8

\title{
Diagnosis
}

The female of $S$. nitens Kuhlmann sp. nov. can be separated from all other species of this group by the combination of the following characters: clypeus almost flat (Fig. 8B); scutum sparsely and coarsely punctate (Fig. 8C); foretibia dominantly dark blackish-brown; stigma brown; apical margins of metasomal terga broadly yellowish-brown; metasomal terga between punctures smooth and shiny (Fig. 8E). The male is unknown.

\section{Etymology}

The name comes from the Latin 'nitens', meaning 'glossy', and referiing to the shiny appearance of the species.

Material examined (1 specimen)

\section{Holotype}

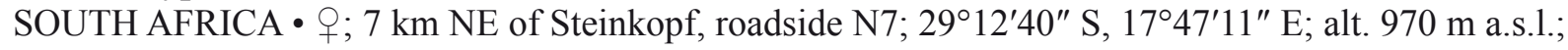
12 Sep. 2017; MK leg.; RCMK.

\section{Description}

\section{Female}

BODY LENGTH. $6.6 \mathrm{~mm}$.

HEAD. Head slightly wider than long. Integument black, except part of mandibles dark reddish-brown. Face sparsely covered with long, greyish, erect hair (Fig. 8B). Clypeus almost flat with relatively coarse and dense $(i=0.5-1.5 \mathrm{~d})$ punctation, apically with slightly sparser punctation $(i=1,5-2,5 \mathrm{~d})$; surface between punctures smooth and shiny (Fig. 8B). Malar area medially narrow, almost linear. Antenna dorsally blackish-brown, ventrally yellowish-brown.

Mesosoma. Integument black, tegula reddish-brown. Mesoscutal disc between punctures smooth and shiny; disc sparsely ( $\mathrm{i}=1.5-3 \mathrm{~d}$ ) and coarsely punctate (Fig. 8C). Metanotum slightly shorter than basal area of propodeum, apically with indistinct narrow carinate depression (Fig. 8D). Propodeum basally only laterally broad and coarsely carinate (Fig. 8D). Mesoscutum, scutellum, metanotum, mesepisternum and propodeum sparsely covered with short, greyish, erect hair (Fig. 8A).

WINGS. Brownish; wing venation and stigma brown.

LEGS. Integument black to dark reddish-brown. Vestiture greyish-white; scopa greyish-white.

METASOMA. Integument black, apical margins of terga narrowly translucent yellowish to reddish-brown (Fig. 8E). Disc of T1-T2 without hair; following terga with very short but increasingly more and longer hair; apical tergal hair bands missing on all terga (Fig. 8E). Prepygidial and pygidial fimbriae yellowish-brown. T1 almost impunctate, T2 $-\mathrm{T} 4$ very sparsely ( $\mathrm{i}=3-5 \mathrm{~d}$ ) and finely (almost invisible) punctate; between punctures smooth and shiny; T2-T4 with polished and shiny apical tergal depression (Fig. 8E).

\author{
Male \\ Unknown.
}

\section{Distribution}

Only known from the type locality NE of Steinkopf. 


\section{Floral hosts}

Aizoaceae: Galenia sarcophylla.

\section{Seasonal activity}

September.
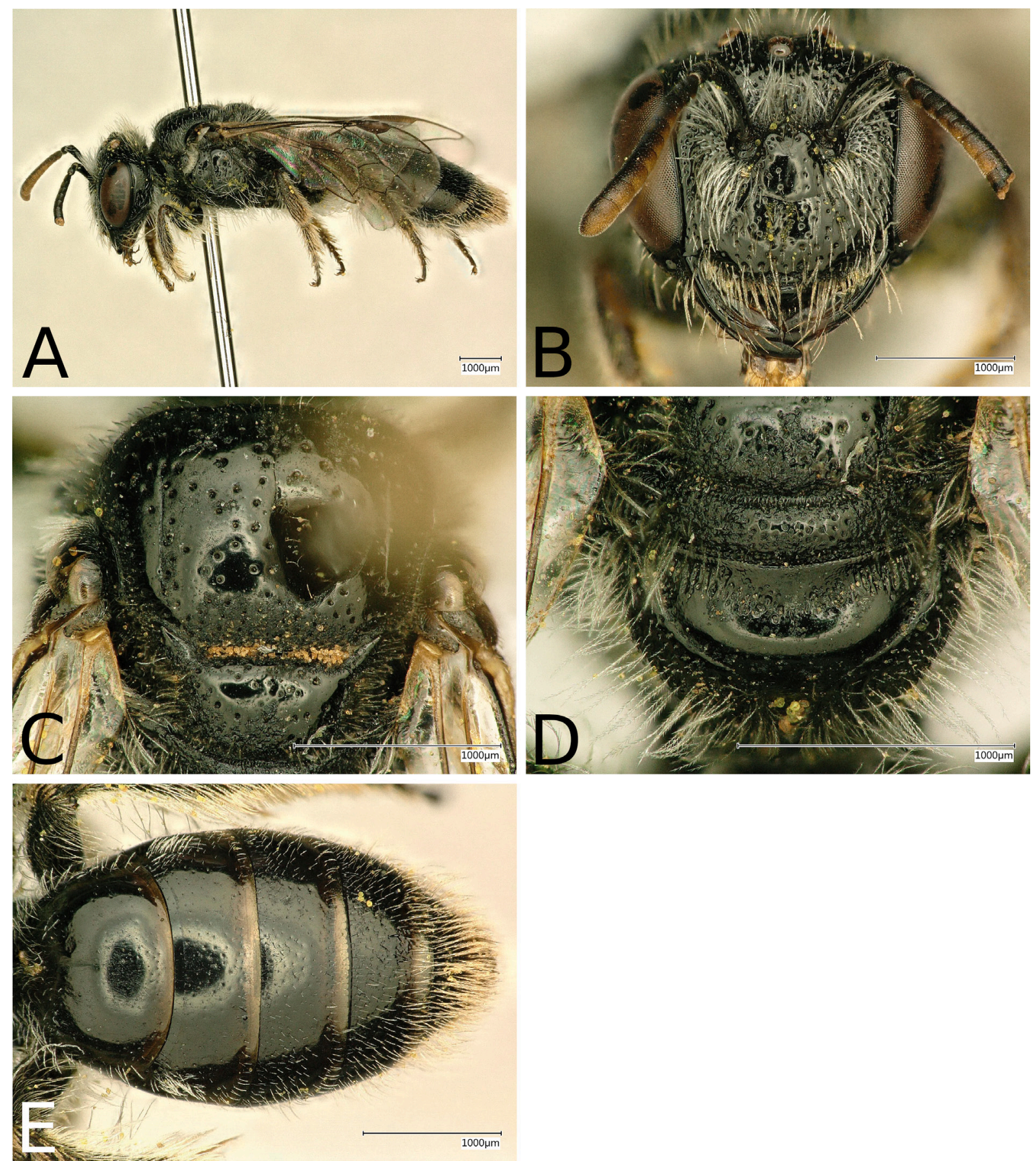

Fig. 8. Scrapter nitens Kuhlmann sp. nov.,, , holotype (RCMK). A. Lateral view. B. Head. C. Scutum and scutellum (dorsal view). D. Metanotum and propodeum (dorsal view). E. Metasoma (dorsal view). 
Scrapter oubergensis Kuhlmann sp. nov. urn:Isid:zoobank.org:act:B4E60FD2-2A77-4135-A575-BE0B4E196F0E

Fig. 9

\section{Diagnosis}

The female of S. oubergensis Kuhlmann sp. nov. can be separated from all other species of this group by the combination of the following characters: supraclypeal area and clypeus coarsely and densely punctate and shiny, only partly superficially sculptured and slightly matt (Fig. 9B); scutum coarsely but relatively densely punctate (Fig. 9C); basal area of propodeum medially about as long as metanotum (Fig. 9D); stigma brown; apical margins of metasomal terga black; terga densely and finely punctate (Fig. 9E). The male is unknown.

\section{Etymology}

Named after the Ouberg Pass southeast of Vanrhynsdorp.

Material examined (2 specimens)

\section{Holotype}

SOUTH AFRICA • P; Ouberg Pass, 27 km SE of Vanrhynsdorp, Fynbos; $31^{\circ} 48^{\prime} 07^{\prime \prime}$ S, $18^{\circ} 55^{\prime} 00^{\prime \prime}$ E; alt. 380 m a.s.1.; 24 Sep. 2014; MK leg.; RCMK.

\section{Paratype}

SOUTH AFRICA • 1 q; same collections data as for holotype; MK leg.; RCMK.

\section{Description}

Female

BODY LENGTH. $5.4 \mathrm{~mm}$.

HEAD. Head wider than long. Integument black, except part of mandibles dark reddish-brown. Face sparsely covered with long, greyish, erect hair (Fig. 9B). Clypeus slightly convex with coarse and relatively dense $(i=1-2 d)$ punctation; surface between punctures superficially sculptured but shiny (Fig. 9B). Malar area medially narrow, almost linear. Antenna dorsally blackish-brown, ventrally yellowish-brown.

Mesosoma. Integument black, tegula dark reddish-brown. Mesoscutal disc between punctures reticulate and slightly matt; disc sparsely ( $\mathrm{i}=1.5-2.5 \mathrm{~d}$ ) and coarsely punctate (Fig. 9C). Metanotum slightly shorter than basal area of propodeum, apically with distinct narrow carinate depression (Fig. 9D). Propodeum basally broadly and coarsely carinate (Fig. 9D). Mesoscutum, scutellum, metanotum, mesepisternum and propodeum sparsely covered with short, greyish, erect hair (Fig. 9A).

WINGS. Yellowish-brown; wing venation and stigma brown.

LEGS. Integument black. Vestiture greyish-brown; scopa greyish-white, dorsally brownish.

METASOMA. Integument black, apical margins of terga narrowly black to translucent dark reddish-brown (Fig. 9E). Disc of T1 without hair; following terga with very short but increasingly more and longer hair; apical tergal hair bands missing on all terga (Fig. 9E); prepygidial and pygidial fimbriae relatively short, blackish-brown. T1 finely and densely $(\mathrm{i}=\mathrm{d})$ punctate, between punctures smooth and shiny; T2T4 slightly coarser punctate; T2 between punctures basally superficially reticulate but shiny, apically smooth; T3-T4 between punctures superficially reticulate and slightly matt; T2-T4 with polished to superficially sculptured, but shiny apical tergal depression (Fig. 9E). 


\section{Male}

Unknown.

\section{Distribution}

Only known from the type locality, a mountain pass in the southern Knersvlakte SE of Vanrhynsdorp.
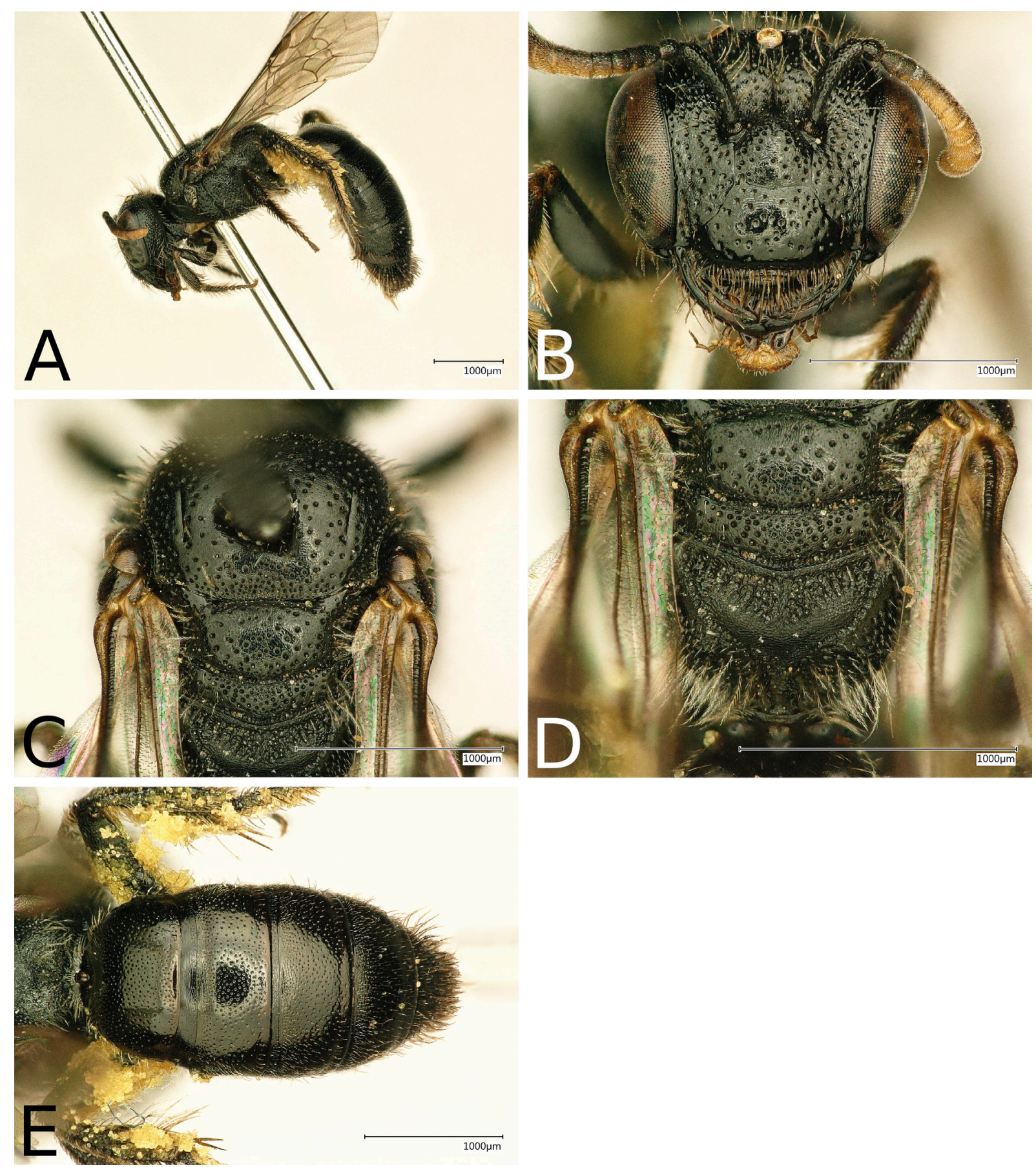

Fig. 9. Scrapter oubergensis Kuhlmann sp. nov., + , holotype (RCMK). A. Lateral view. B. Head. C. Scutum and scutellum (dorsal view). D. Metanotum and propodeum (dorsal view). E. Metasoma (dorsal view). 


\section{Floral hosts}

Brassicaceae: blue Heliophila spec.

\section{Seasonal activity}

September.

Scrapter willemstrydomi Kuhlmann sp. nov. urn:1sid:zoobank.org:act:F38FC747-E1B7-4781-AA9B-D1AFC6011650

Fig. 10

\section{Diagnosis}

The male of $S$. willemstrydomi Kuhlmann sp. nov. can be separated from all other species of this group by its hind tibia with a long, broadened spine, the apically swollen hind basitarsus and the triangular broadened third hind tarsus (Fig. 10E). The female is unknown.

\section{Etymology}

This species is dedicated to the sculptor and painter Willem Strydom $\left({ }^{\circ} 30\right.$ June $1954-† 2$ June 2019) from Matjiesfontein south of Nieuwoudtville. The bee is as unique as he was. Willem encouraged me (MK) to explore remote mountainous regions, especially between Calvinia and Sutherland, and he generously shared his passion and knowledge about this area, which over the years has led to the discovery of numerous new species.

Material examined (1 specimen)

\section{Holotype}

SOUTH AFRICA • ${ }^{`}$; Kamiesberg Mts, $5 \mathrm{~km}$ SE of Leliefontein, roadside; $30^{\circ} 20^{\prime} 09^{\prime \prime} \mathrm{S}, 18^{\circ} 06^{\prime} 24^{\prime \prime} \mathrm{E}$; alt. $1400 \mathrm{~m}$ a.s.1.; 11 Sep. 2016; MK leg.; RCMK.

\section{Description}

\section{Female}

Unknown.

\section{Male}

Body LeNGTH. $5.9 \mathrm{~mm}$.

HEAD. Head slightly wider than long. Integument black, except mandible partly dark

reddish-brown. Face covered with long, greyish-white, erect hair. Malar area medially narrow, almost linear. Antenna dorsally dark brown, ventrally yellowish-brown (Fig. 10A).

Mesosoma. Integument black. Mesoscutal disc between punctures superficially reticulate and slightly matt; disc relatively densely ( $\mathrm{i}=1-1.5 \mathrm{~d}$ ) but coarsely punctate. Mesoscutum, scutellum, metanotum, mesepisternum and propodeum covered with long, greyish, erect hair (Fig. 10A).

WINGS. Slightly yellowish-brown; wing venation and stigma brown.

LEGS. Integument black, fore tibia in basal half anteriorly yellow. Hind tibia inside apically broadened, with a long, broadened spine (Fig. 10E). Hind basitarsus medially broadened, third hind tarsus apically triangular broadened (Fig. 10E). Vestiture greyish-white. 
METASOMA. Integument black, apical margins of terga partly narrowly translucent reddish-brown (Fig. 10C). Disc of T1 without hair, following terga with sparse and short but increasingly more and longer hair; apical tergal hair bands missing on all terga (Fig. 10C). T1 densely ( $i=0.5-1 \mathrm{~d}$ ) but relatively finely, following terga slightly coarser punctate; between punctures polished to superficially sculptured and shiny to slightly matt; T2-T4 with narrow, polished to superficially sculptured but shiny apical tergal depression (Fig. 10C). S3 and particularly S4-S5 with sparse, long apical hair fringes.
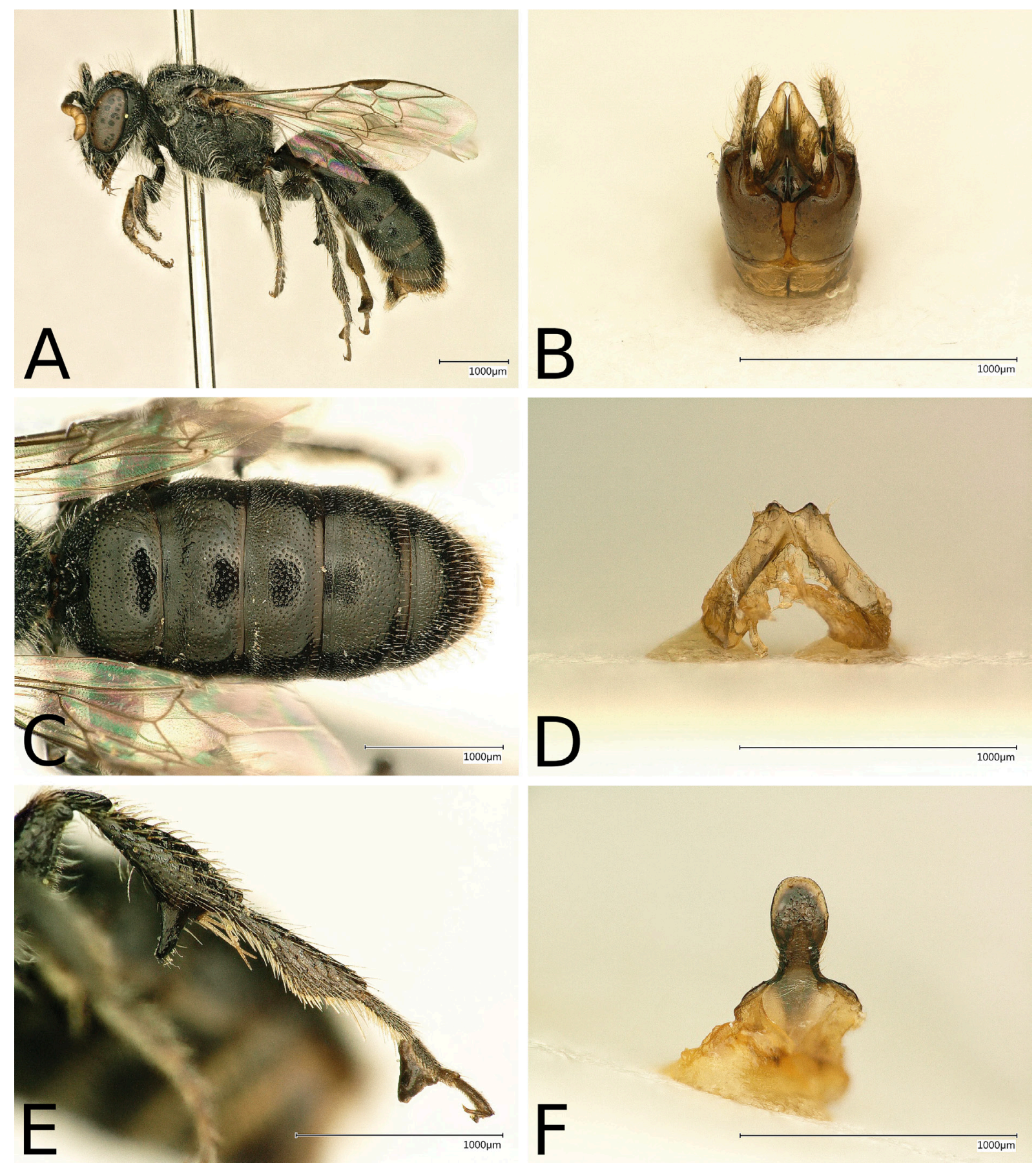

Fig. 10. Scrapter willemstrydomi Kuhlmann sp. nov., §̂, holotype (RCMK). A. Lateral view. B. Genitalia (dorsal view). C. Metasoma (dorsal view). D. S7 (dorsal view). E. Hind leg. F. S8, apical end. 
Terminalia. Genitalia (Fig. 10B), S7 (Fig. 10D) and terminal plate of S8 (Fig. 10F) as illustrated.

\section{Distribution}

Only known from the type locality in the Kamiesberg Mts.

\section{Floral hosts}

Unknown.

\section{Seasonal activity}

September.

\section{New records of described species of euryglossiform Scrapter}

New records of the known species of euryglossiform Scrapter, described in Kuhlmann (2014), are listed below.

Scrapter acanthophorus Davies, 2005

Scrapter acanthophorus Davies, 2005: 153-155, figs 4-8.

Material examined ( 2 specimens)

SOUTH AFRICA • 2 q 9 ; 8 km WNW of Leliefontein, Fynbos, roadside; $30^{\circ} 15^{\prime} 58^{\prime \prime}$ S, $18^{\circ} 03^{\prime} 17^{\prime \prime}$ E; alt. 1190 m a.s.1.; 14 Sep. 2017; MK leg.; RCMK.

\section{Distribution}

This is the first record outside the semi-desert plane of the Knersvlakte and a significant range extension to the north into the Kamiesberg Mts.

\section{Scrapter albitarsis (Friese, 1909)}

Polyglossa albitarsis Friese, 1909: 87, 124.

Material examined (133 specimens)

SOUTH AFRICA • 3 우, 1 §̊; $12 \mathrm{~km}$ NW of Nieuwoudtville, Farm Avontuur, Fynbos; $31^{\circ} 16^{\prime} 18^{\prime \prime} \mathrm{S}$,

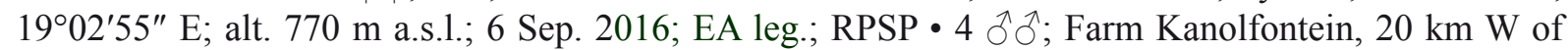

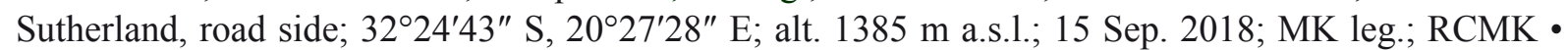
5 우, 1 `; Gemsbokrivier-Pad, $4.5 \mathrm{~km} \mathrm{NE}$ of Grootdrif, road side; $31^{\circ} 25^{\prime} 54^{\prime \prime} \mathrm{S}, 18^{\circ} 55^{\prime} 16^{\prime \prime} \mathrm{E}$; alt. 170 m a.s.1.; 4 Sep. 2016; MK leg.; RCMK • 1 q; same collection data as for preceding; 6 Sep. 2016; MK

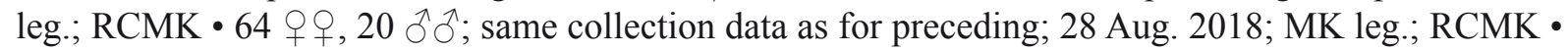

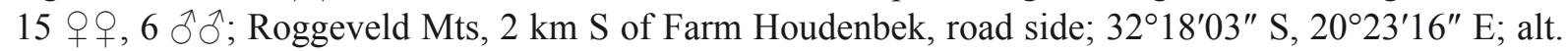
1280 m a.s.1.; 16 Sep. 2018; MK leg.; RCMK • 1 §; Roggeveld Mts, 2 km SE of Farm Allemansdam,

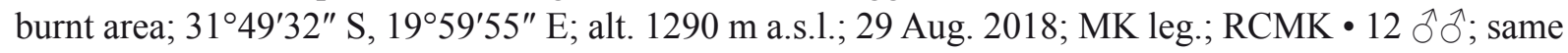
collection data as for preceding; 10 Sep. 2018; MK leg.; RCMK.

\section{Distribution}

The species is widespread in the winter rainfall region of western South Africa.

Scrapter exiguus Kuhlmann, 2014

Scrapter exiguus Kuhlmann, 2014: 12-16, figs 6-7. 
Material examined (24 specimens)

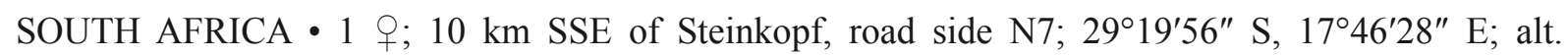

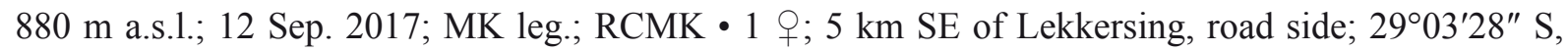
$17^{\circ} 07^{\prime} 16^{\prime \prime}$ E; alt. $300 \mathrm{~m}$ a.s.1.; 10 Sep. 2016; MK and EA leg.; RCMK • 1 \%; same collection data as

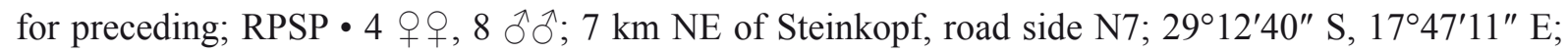
alt. 970 m a.s.1.; 12 Sep. 2017; MK leg.; RCMK • 1 \%; same collection data as for preceding; 13 Sep. 2017; MK leg.; RCMK • 2 q 9 ; Kamiesberg Mts, 18 km ENE of Kamieskroon, road side; $30^{\circ} 09^{\prime} 11^{\prime \prime}$ S, $18^{\circ} 06^{\prime} 15^{\prime \prime}$ E; alt. 950 m a.s.1.; 6 Oct. 2014; MK leg.; RCMK • 1 '̊; Keiski Mts, 3 km E of Farm M'Vera,

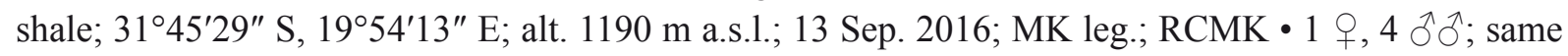
collection data as for preceding; 15 Sep. 2016; MK leg.; RCMK.

\section{Distribution}

Scrapter exiguus is apparently widely distributed in Namaqualand.

Scrapter luteistigma Kuhlmann, 2014

Scrapter luteistigma Kuhlmann, 2014: 22-25, figs 11-12.

Material examined (10 specimens)

SOUTH AFRICA • 10 q ; Gemsbokrivier-Pad, $4.5 \mathrm{~km}$ NE of Grootdrif, roadside; $31^{\circ} 25^{\prime} 54^{\prime \prime} \mathrm{S}$, $18^{\circ} 55^{\prime} 16^{\prime \prime}$ E; alt. 170 m a.s.1.; 28 Aug. 2018; MK leg.; RCMK.

\section{Distribution}

Scrapter luteistigma is only known from the semi-desert plane of the Knersvlakte.

Scrapter nanus Kuhlmann, 2014

Scrapter nanus Kuhlmann, 2014: 32-35, figs 16-17.

Material examined ( 47 specimens)

SOUTH AFRICA • 3 우 $12 \mathrm{~km} \mathrm{NW}$ of Nieuwoudtville, Farm Avontuur, Fynbos; $31^{\circ} 16^{\prime} 18^{\prime \prime} \mathrm{S}$, $19^{\circ} 02^{\prime} 55^{\prime \prime}$ E; alt. $770 \mathrm{~m}$ a.s.1.; 3 Sep. 2016; MK leg.; RCMK • 4 qo ; same collection data as for preceding; 6 Sep. 2016; MK leg.; RCMK・ 2 ठో ; same collection data as for preceding; 23 Aug. 2017; MK leg.; RCMK • 8 $\widehat{\jmath}$; same collection data as for preceding; 25 Aug. 2017; MK leg.; RCMK • 4 우,

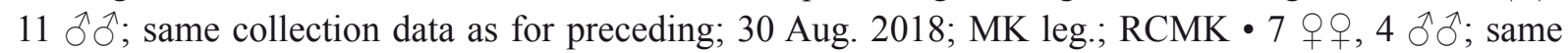
collection data as for preceding; 9 Sep. 2018; MK leg.; RCMK • 3 우; $20 \mathrm{~km} \mathrm{~S}$ of Nieuwoudtville,

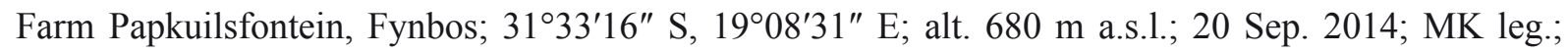
RCMK • 1 万'; Cederberg Mts, road to Algeria, Olifants River bridge; $32^{\circ} 21^{\prime} 55^{\prime \prime} \mathrm{S}, 18^{\circ} 57^{\prime} 06^{\prime \prime} \mathrm{E}$; alt. 150 m a.s.1.; 8 Sep. 2017; MK leg.; RCMK.

\section{Distribution}

The species was previously only known from the wider Nieuwoudtville area so the record from the Cederberg Mts is a significant range extension to the south.

Scrapter papkuilsi Kuhlmann, 2014

Scrapter papkuilsi Kuhlmann, 2014: 41-44, figs 21-22. 
Material examined ( 9 specimens)

SOUTH AFRICA • 4 ㅇ; 20 km S of Nieuwoudtville, Farm Papkuilsfontein, Fynbos; 31 33'16" S,

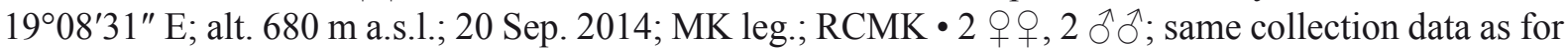
preceding; 26 Aug. 2016; MK leg.; RCMK • 1 q; same collection data as for preceding; 30 Aug. 2018; MK leg.; RCMK.

\section{Distribution}

Scrapter papkuilsi is only known from the Bokkeveld Plateau north and south of Nieuwoudtville.

Scrapter punctulatus Kuhlmann nom. nov.

First, Willem Coetzer, South African Institute for Aquatic Biodiversity, Grahamstown (South Africa), and later independently Vladimir G. Radchenko, Institute of Evolutionary Ecology of the National Academy of Sciences of Ukraine, Kiev (Ukraine), pointed out to me (MK) that Scrapter punctatus Kuhlmann, 2014 is a primary junior homonym of S. punctatus Lepeletier \& Audinet-Serville, 1825 (= Allodape punctata [Lepeletier \& Audinet-Serville, 1825]) (Eardley \& Urban 2010 ). There is no known synonym of the junior homonym so following article 60.3 ICZN the new substitute name S. punctulatus nom. nov. is here proposed for S. punctatus Kuhlmann, 2014.

Material examined (1 specimen)

SOUTH AFRICA • 1 क; Kamiesberg Mts, $5 \mathrm{~km} \mathrm{SE}$ of Leliefontein, roadside; $30^{\circ} 20^{\prime} 09^{\prime \prime} \mathrm{S}, 18^{\circ} 06^{\prime} 24^{\prime \prime} \mathrm{E}$; alt. 1400 m a.s.1.; 7 Sep. 2016; MK leg.; RCMK.

\section{Distribution}

The species is only known from the Kamiesberg Mts.

Scrapter sittybon Davies, 2005

Scrapter sittybon Davies, 2005: 171-173, figs 36-39.

Material examined (49 specimens)

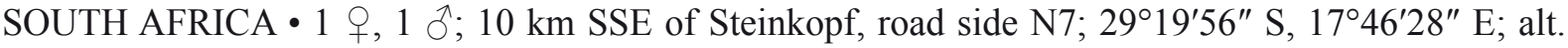
880 m a.s.1.; 12 Sep. 2017; MK leg.; RCMK • 21 우; 5 km SE of Lekkersing, road side; 29 $03^{\prime \prime 2} 28^{\prime \prime}$ S,

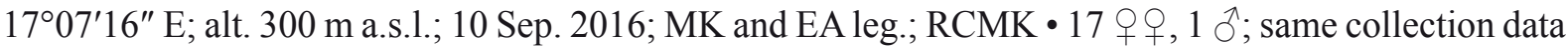

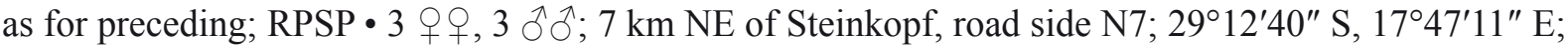
alt. $970 \mathrm{~m}$ a.s.1.; 12 Sep. 2017; MK leg.; RCMK・2 त̂ं; Gemsbokrivier-Pad, $4.5 \mathrm{~km} \mathrm{NE}$ of Grootdrif, road side; $31^{\circ} 25^{\prime} 54^{\prime \prime}$ S, $18^{\circ} 55^{\prime} 16^{\prime \prime}$ E; alt. 170 m a.s.1.; 28 Aug. 2018; MK leg.; RCMK.

\section{Distribution}

The records from the Steinkopf vicinity are a significant northward range extension of S. sittybon.

Scrapter spinipes Kuhlmann, 2014

Scrapter spinipes Kuhlmann, 2014: 58-61, figs 30-31.

Material examined (68 specimens)

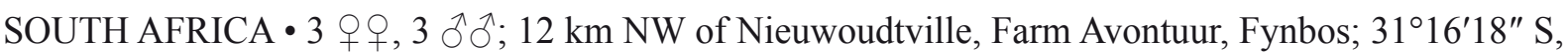
$19^{\circ} 02^{\prime} 55^{\prime \prime}$ E; alt. $770 \mathrm{~m}$ a.s.1.; 3 Sep. 2016; MK leg.; RCMK • 6 우; same collection data as for preceding; 6 Sep. 2016; MK and EA leg.; RCMK • 2 + $\odot$; same collection data as for preceding; RPSP• 


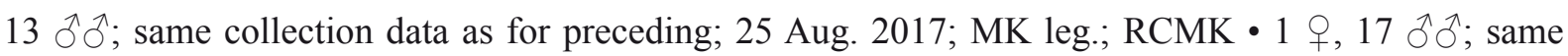

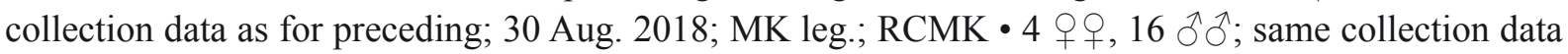
as for preceding; 9 Sep. 2018; MK leg.; RCMK • 1 + ; Gemsbokrivier-Pad, 4.5 km NE of Grootdrif, road

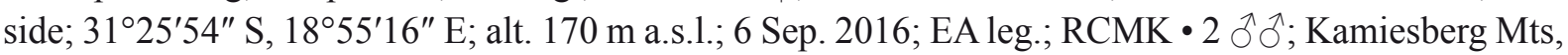
$5 \mathrm{~km}$ SE of Leliefontein, road side; $30^{\circ} 20^{\prime} 09^{\prime \prime}$ S, $18^{\circ} 06^{\prime} 24^{\prime \prime}$ E; alt. $1400 \mathrm{~m}$ a.s.1.; 10 Sep. 2017; MK leg.; RCMK.

\section{Distribution}

Scrapter spinipes was collected for the first time in the semi-desert plain of the Knersvlakte and the Kamiesberg Mts. The latter is a significant northward range extension.

Scrapter ulrikae Kuhlmann, 2014

Scrapter ulrikae Kuhlmann, 2014: 61-65, figs 32-33.

Material examined (32 specimens)

SOUTH AFRICA • 2 우, 1 万’; 12 km NW of Nieuwoudtville, Farm Avontuur, Fynbos; $31^{\circ} 16^{\prime} 18^{\prime \prime} \mathrm{S}$, 1902'55" E; alt. $770 \mathrm{~m}$ a.s.1.; 3 Sep. 2016; MK leg.; RCMK • 2 $+q$; same collection data as for preceding; 6 Sep. 2016; MK and EA leg.; RCMK • 1 क; same collection data as for preceding; RPSP • 1 영 same collection data as for preceding; 25 Aug. 2017; MK leg.; RCMK • 2 우; 8 km WNW of Leliefontein, Fynbos, road side; 30¹5'58" S, 1803'17" E; alt. 1190 m a.s.1.; 10 Sep. 2017; MK leg.; RCMK・ 1 q; same collection data as for preceding; 14 Sep. 2017; MK leg.; RCMK・ 1 + ; Kamiesberg Mts, $5 \mathrm{~km} \mathrm{SE}$ of Leliefontein, road side; 30²0'09" S, 1806'24" E; alt. 1400 m a.s.1.; 7 Sep. 2016; MK and EA leg.; RCMK • 3 q $q$; same collection data as for preceding; RPSP・ 9 q $q$; same collection data as for preceding; 11 Sep. 2016; MK and EA leg.; RCMK • 5 q $q$; same collection data as for preceding;

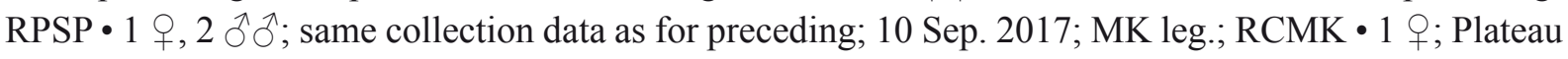
Hantam Mts, near antenna, $9 \mathrm{~km} \mathrm{~N}$ of Calvinia; 31 ${ }^{\circ} 22^{\prime 2} 9^{\prime \prime}$ S, $19^{\circ} 47^{\prime} 03^{\prime \prime}$ E; alt. $1570 \mathrm{~m}$ a.s.1.; 14 Oct. 2014; MK leg.; RCMK・ 1 §`; Roggeveld Mts, 2 km SE of Farm Allemansdam, burnt area; 31 ${ }^{\circ} 49^{\prime} 32^{\prime \prime}$ S, 1959'55" E; alt. 1290 m a.s.1.; 2 Sep. 2017; MK leg.; RCMK.

\section{Distribution}

The records of S. ulrikae from the Kamiesberg Mts are a significant range extension to the north.

\section{Key to species of euryglossiform Scrapter}

Here, we provide an updated key for the identification of euryglossiform Scrapter, by Kuhlmann (2014), including the newly described species.

\section{Females}

The females of S. glareus, S. hergi Kuhlmann sp. nov., S. minutissimus and S. willemstrydomi Kuhlmann sp. nov. are unknown.

1. Stigma bright yellow (Kuhlmann 2014: Fig. 11a) .................. S. luteistigma Kuhlmann, 2014

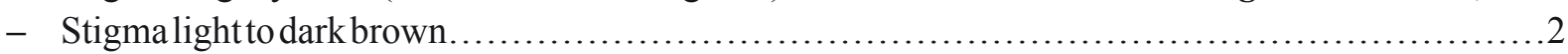

2. Apical tergal margins broadly brownish to yellowish translucent(Figs 3E, 8E; Kuhlmann 2014: figs 1b,

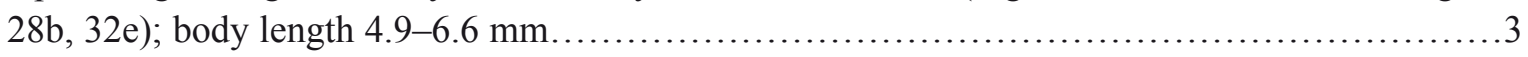

- Apical tergal margins black or very narrowly brownish translucent; body length $4.3-5.6 \mathrm{~mm} \ldots \ldots .7$ 
3. Punctation on basal part of clypeus much finer than apically (Kuhlmann 2014: fig. 28c-d); foretibia entirely or predominantly yellowish to reddish brown (Kuhlmann 2014: fig. 28a)........

S. sittybon Davies, 2005

- Punctation on clypeus more evenly sized (Figs 3B, 8B; Kuhlmann 2014: figs 1c-d, 32b); foretibia dominantly dark blackish-brown..........................................................

4. Metasomal terga between punctures smooth and shiny (Fig. 8E; Kuhlmann 2014: fig. 1b) ........5

- Metasomal terga between punctures at least finely sculptured and slightly matt (Fig. 3E; Kuhlmann 2014: fig. 32e).

5. Clypeus distinctly convex (Kuhlmann 2014: fig. 1c-d); scutum with dense punctation (Kuhlmann 2014: fig. 1e-f).

S. acanthophorus Davies, 2005

- Clypeus almost flat (Fig. 8B); scutum with sparse punctation (Fig. 8C)...S. nitens Kuhlmann sp. nov.

6. Clypeus between punctures smooth and shiny (Kuhlmann 2014: fig. 32b); scutum superficially reticulate but shiny (Kuhlmann 2014: fig. 32c-d).

S. ulrikae Kuhlmann, 2014

- Clypeus between punctures superficially sculptured and slightly matt (Fig. 3B); scutum reticulate and matt (Fig. 3C) ....................................... fynbosensis Kuhlmann sp. nov.

7. Scutum sparsely and finely punctured, looking almost impunctate and shiny (Kuhlmann 2014: figs $6 \mathrm{e}-\mathrm{f}, 8 \mathrm{e}-\mathrm{f})$.

- Scutum more densely and coarsely punctured......................................... 10

8. Supraclypeal area, clypeus (Kuhlmann 2014: fig. 6c-d) and mesepisternum only partially and superficially reticulate, more shiny....

S. exiguus Kuhlmann, 2014

- Supraclypeal area apically, clypeus basally (Kuhlmann 2014: fig. 8c-d) and mesepisternum extensively and strongly reticulate, matt.

9. Facial fovea slightly shorter than in S. gessorum (Kuhlmann 2014: fig. 4a-b); a variable species with respect to surface sculpture and punctation (Kuhlmann 2014: figs 3c-f, 4a-d). ...

S. albitarsis (Friese, 1909)

- Facial fovea slightly longer than in S. albitarsis (Kuhlmann 2014: fig. 8d)

S. gessorum Kuhlmann, 2014

10. Clypeus and supraclypeal area matt, strongly reticulate, very sparsely, finely and shallowly punctate (Kuhlmann 2014: fig. 10c-d).

S. inexpectatus Kuhlmann, 2014

- Clypeus and supraclypeal area more shiny or just slightly matt, only partly or superficially sculptured, punctation usually stronger and denser.

11. Metasomal terga finely and densely punctate, between punctures smooth and shiny (Fig. 2E; Kuhlmann 2014: fig. 18b).

- Metasomal terga either impunctate or with more dispersed/coarser punctation; if punctation is similar (some specimens of S. punctatus), then terga at least basally with superficial sculpture and slightly matt

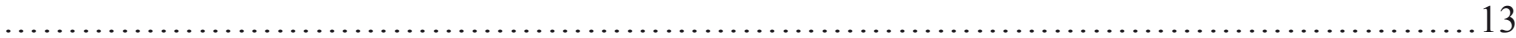

12. Scutum very densely ( $i=0,5-1$ d) punctate (Kuhlmann 2014: fig. 18e-f), propodeum basally shallowly but broadly carinate (Kuhlmann 2014: fig. 18f)......S. nigerrimus Kuhlmann, 2014

- Scutum coarser $(\mathrm{i}=1-2,5 \mathrm{~d})$ punctate (Fig. 2C), propodeum basally only laterally with distinct but fine carination (Fig. 2D)...

S. bokkeveldensis Kuhlmann sp. nov.

13. Metasomal terga impunctate; scutum distinctly reticulate and shallowly punctate.............14

- Metasomal terga punctate, sometimes punctures minute.................................. 15 
14. Basal area of propodeum distinctly and largely carinate (Kuhlmann 2014: fig. 19b)

S. nigritarsis Kuhlmann, 2014

- Basal area of propodeum along anterior margin indistinctly carinate (Kuhlmann 2014: fig. 25c-d)...

S. pygmaeus Kuhlmann, 2014

15. Scutum very coarsely punctate (Fig. 9C; Kuhlmann 2014: figs 23c-d, 30c-d)..........16

- Scutum finer punctate (Figs 1C, 6C-D, 5C; Kuhlmann 2014: figs 14e-f, 15c-d, 16e-f, 21c-f, 26c-

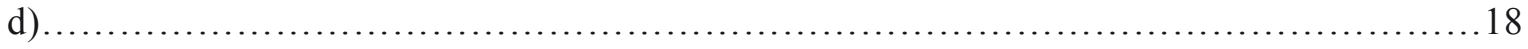

16. Propodeum basally broadly and distinctly carinate (Fig. 9D; Kuhlmann 2014: fig. 30c-d).....17

- Propodeum with few, short and indistinct carinae (Kuhlmann 2014: fig. 23c-d)....

S. punctulatus Kuhlmann nom. nov.

17. Basal area of propodeum shorter, medially only slightly longer than metanotum (Fig. 9D).

S. oubergensis Kuhlmann sp. nov.

- Basal area of propodeum longer, medially about 1.5 times as long as metanotum (Kuhlmann 2014: fig. 30c-d).

S. spinipes Kuhlmann, 2014

18. Punctation of metasomal terga minute, almost invisible (Kuhlmann 2014: fig. 26e).

S. roggeveldi Kuhlmann, 2014

- Punctation of metasomal terga much coarser and clearly visible (Figs 1C, 6C-D, 5C; Kuhlmann

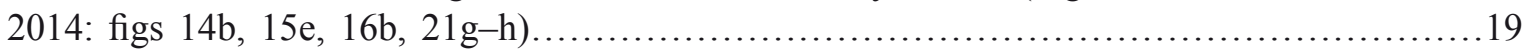

19. Head distinctly broader than long (Figs 1C, 6C-D, 5C; Kuhlmann 2014: figs 14c-d, 16c-d) .....20

- Head about as long as broad (Kuhlmann 2014: figs 15b, 21b)..............................24

20. Clypeus, supraclypeal area and T1 mostly polished and shiny, only partially very finely and superficially sculptured, slightly matt (Kuhlmann 2014: fig. 14b-d)..........S. minutuloides Kuhlmann, 2014

- Clypeus, supraclypeal area and T1 (particularly anteriorly) mostly finely sculptured and matt

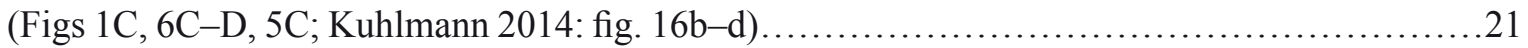

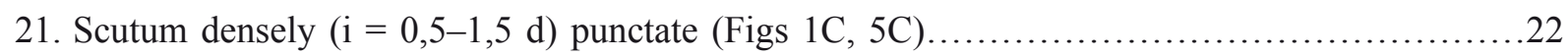

- Scutum sparsely (i > 1,5 d) punctate (Fig. 6C-D; Kuhlmann 2014: fig. 16e-f)..................23

22. Propodeum basally distinctly and broadly carinate (Fig. 1D)... S. avontuuensis Kuhlmann sp. nov.

- Propodeum basally only indistinctly and shallowly carinate (Fig. 5D).

S. keiskiensisKuhlmann sp. nov.

23. Propodeum basally distinctly and broadly carinate (Kuhlmann 2014: fig. 16e-f)

S. nanus Kuhlmann, 2014

- Propodeum basally finer and just very shallowly carinate, sometimes just laterally visible (Fig. 6EF). S. mellonholgeri Kuhlmann sp. nov.

24. Metanotum apically more evenly rounded, without distinct carinate depression (Kuhlmann 2014: fig. 15d); fore tibia anteriorly largely yellowish-brown........S. minutus Kuhlmann, 2014

- Metanotum apically with a carinate depression (Kuhlmann 2014: fig. 21d, f); fore tibia anteriorly blackish, only at the base with a small yellowish spot

S. papkuilsi Kuhlmann, 2014

\section{Males}

The males of $S$. avontuurensis Kuhlmann sp. nov., S. bokkeveldensis Kuhlmann sp. nov., S. fynbosensis Kuhlmann sp. nov., S. gessorum, S. inexpectatus, S. keiskiensis Kuhlmann sp. nov., S. minutuloides, 
S. minutus, S. nigerrimus, S. nitens Kuhlmann sp. nov., S. oubergensis Kuhlmann sp. nov. and S. pygmaeus are unknown.

1. Antennal flagellum medially broadened, entirely orange (Kuhlmann 2014: fig. 12b); stigma bright yellow (Kuhlmann 2014: Fig. 12a); S7 and S8 as in Kuhlmann (2014: fig. 12d, f).

S. luteistigma Kuhlmann, 2014

- Antennal flagellum not broadened, only partly yellowish; stigma darker. .2

2. Third hind tarsus triangular broadened (Fig. 10E)..........S. willemstrydomi Kuhlmann sp. nov.

- Third hind tarsus unmodified.................................................................

3. Antenna long, last flagellar segment about twice as long as wide (Kuhlmann 2014: fig. 24e); S7 and S8 as in Kuhlmann (2014: fig. 24d, f)...................... p. punctulatus Kuhlmann nom. nov.

- Antenna shorter, last flagellar segment at most 1.5 times as long as wide...................

4. Hind tibia inside apically broadened, pointed (Kuhlmann 2014: fig. 22e) or forming either a spine (Fig. 7E; Kuhlmann 2014: figs 2e, 31e) or a \pm right angle (Fig. 4G; Kuhlmann 2014: fig. 27g) .....5

- Hind tibia unmodified, if apically broadened then without spine or \pm sharp edge..............10

5. Hind tibia inside apically forming a \pm right angle (Fig. 4G; Kuhlmann 2014: fig. 27g)...........6

- Hind tibia inside apically pointed (Kuhlmann 2014: Fig. 22e) or forming a spine (Fig. 7E;

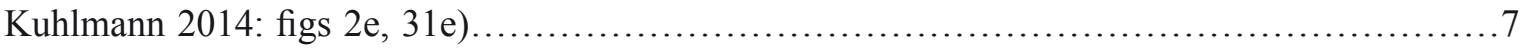

6. Body about $5 \mathrm{~mm}$ long; hind tibia forming a distinct right angle (Kuhlmann 2014: fig. 27g); S7 and S8 as in Kuhlmann (2014: fig. 27d, f)......................S. roggeveldi Kuhlmann, 2014

- Body longer; hind tibia forming a shallow right angle (Fig. 4G); S7 and S8 as in Fig. 4F, H..... S. hergi Kuhlmann sp. nov.

7. Hind tibia inside apically pointed (Kuhlmann 2014: fig. 22e); scutum and metasomal terga finely punctate (Kuhlmann 2014: fig. 22c); S7 and S8 as in Kuhlmann (2014: fig. 22d, f) .......................................................... papkuilsi Kuhlmann, 2014

- Hind tibia inside apically with spine (Fig. 7E; Kuhlmann 2014: figs 2e, 31e)..............8

8. Scutum and metasomal terga coarsely punctate (Kuhlmann 2014: figs 2c, 31c)...........9

- Scutum coarsely and metasomal terga finely punctate(Fig. 7C)...S. mellonholgeri Kuhlmann sp. nov.

9. Hind tibia apically with longer spine (Kuhlmann 2014: fig. 31e); metasomal terga densely punctate (Kuhlmann 2014: Fig. 31c); S7 and S8 as in Kuhlmann(2014: fig. 31d,f) ...S. spinipes Kuhlmann, 2014

- Hind tibia apically with shorter spine (Kuhlmann 2014: fig. 2e); metasomal terga sparsely punctate (Kuhlmann 2014:fig. 2c); S7 and S8 as in Kuhlmann(2014:fig. 2d,f)...S. acanthophorus Davies, 2005

10. Hind basitarsus brown to blackish....................................................... 11

- Hind basitarsus yellowish...............................................................

11. Hind tibia apically slightly swollen and curved (Kuhlmann 2014: fig. 29e); scutum between punctures smooth and shiny; S7 and S8 as in Kuhlmann (2014: fig. 29d, f)...S. sittybon Davies, 2005

- Hind tibia unmodified; scutum between punctures sculptured and matt....................12

12. Basal half of T2-T4 densely covered with short, silverish hair (Kuhlmann 2014: fig. 33c); S7 and S8 as in Kuhlmann (2014: fig. 33d-e)...................S. ulrikae Kuhlmann, 2014

- Basal half of T2-T4 almost hairless (Kuhlmann 2014: figs 17c, e, 20c)......................13 
13. Discs of metasomal terga impunctate, very finely and regularly sculptured (Kuhlmann 2014: fig. 20c); S7 and S8 as in Kuhlmann (2014: fig. 20d-e).

S. nigritarsis Kuhlmann, 2014

- Discs of metasomal terga partly punctate, strongly to heavily and irregularly sculptured (Kuhlmann 2014: fig. 17c, e); S7 and S8 as in Kuhlmann(2014: fig. 17d, f). ...

S. nanus Kuhlmann, 2014

14. Hind tibia yellow with a brown spot on the back side (Kuhlmann 2014: fig. 9a, c); S7 and S8 as in Kuhlmann (2014: fig. 9d-e).

S. glareus Davies, 2005

- Hind tibia mostly black (Kuhlmann 2014: figs 5a, 7a, 13a)....

The males of the following three species are very similar and can be best separated by S7 and S8.

15. S7 without membraneous apicolateral lobes (Kuhlmann 2014: fig. 13d); S8 as in Kuhlmann (2014: fig. 13e).

- S7 with membraneous apicolateral lobes (Kuhlmann 2014: figs 5d, 7d).

16. S7 apically with emargination slightly broader and shallower (Kuhlmann 2014: fig. 5d)

S. albitarsis (Friese, 1909)

- S7 apically with emargination slightly narrower and deeper (Kuhlmann 2014: fig. 7d)....

S. exiguus Kuhlmann, 2014

\section{Discussion}

In the present study, nine new species of the bee genus Scrapter are described, bringing the total number to 68 and increasing the number of euryglossiform Scrapter by $45 \%$ to 29 . In addition, new records are presented for ten species, partly resulting in a significant extension of the known ranges for some of them. We decided to describe eight of the new species based on one or two specimens only because they showed unique traits not present in related species and the range of variation in all related species is such that there is no overlap of traits. Naming these species is also meant to point out the urgent need for a better documentation of a unique and rich endemic bee fauna in the Greater Cape Floristic Region, which is particularly vulnerable to and affected by climate change (Kuhlmann et al. 2012).

Almost all of the new species were collected in South Africa over the last five years, despite the unfavourable drought conditions, indicating that the new species described in this paper probably represent only part of the true diversity of the group. The discovery of numerous new species, many of them represented only by a single specimen, over a short period of time in a relatively small region highlights the need for more collecting effort even in relatively well sampled regions of the GCFR. This is also supported by the fact that 17 of the 29 species of euryglossiform Scrapter are only known from females and four only from the male sex.

\section{Acknowledgements}

The first author would like to thank Willem Coetzer, South African Institute for Aquatic Biodiversity, Grahamstown (South Africa), and Vladimir G. Radchenko, Institute of Evolutionary Ecology of the National Academy of Sciences of Ukraine, Kiev (Ukraine), for pointing out the primary junior homonymy of S. punctatus. The Department of Environment and Nature Conservation (Northern Cape Province) and CapeNature (Western Cape Province) are gratefully acknowledged for giving their permission to collect bees. Noel Oettle, Managing Director of Avontuur Sustainable Agriculture, and Willem van Wyk (Papkuilsfontein) granted access to the respective properties and gave permission for bee collecting. My wife Ulrike Gigengack actively and enthusiastically supported fieldwork and added many valuable specimens to the collection. 


\section{References}

Almeida E.A.B. \& Danforth B.N. 2009. Phylogeny of colletid bees (Hymenoptera: Colletidae) inferred from four nuclear genes. Molecular Phylogenetics and Evolution 50: 290-309.

https://doi.org/10.1016/j.ympev.2008.09.028

Almeida E.A.B., Pie M.R., Brady S.G. \& Danforth B.N. 2012. Biogeography and diversification of colletid bees (Hymenoptera: Colletidae): emerging patterns from the southern end of the World. Journal of Biogeography 39: 526-544. https://doi.org/10.1111/j.1365-2699.2011.02624.x

Davies G.B.P. \& Brothers D.J. 2006. Morphology of Scrapter (Hymenoptera: Anthophila: Colletidae), with description of three new species and taxonomic status of five Cockerell taxa. African Invertebrates 47: $135-183$.

Davies G.B.P., Eardley C.D. \& Brothers D.J. 2005. Eight new species of Scrapter (Hymenoptera: Apoidea: Colletidae), with descriptions of S. albifumus and S. amplispinatus females and a major range extension of the genus. African Invertebrates 46: 141-179.

Eardley C.D. \& Urban R. 2010. Catalogue of Afrotropical bees (Hymenoptera: Apoidea: Apiformes). Zootaxa 2455: 1-548.

Eardley C.D. 1996. The genus Scrapter Lepeletier \& Serville (Hymenoptera: Colletidae). African Entomology 4: 37-92.

Friese H. 1909. Die Bienen Afrikas nach dem Stande unserer heutigen Kenntnisse. In: Schultze L. (ed.) Zoologische und Anthropologische Ergebnisse einer Forschungsreise im westlichen und zentralen Südafrika ausgeführt in den Jahren 1903-1905, Band 2. Denkschriften der Medizinischnaturwissenschaftlichen Gesellschaft zu Jena 14: 83-476.

Harris R.A. 1979. A glossary of surface sculpturing. Occasional Papers in Entomology 28: 1-31.

Kayaalp P., Stevens M.I. \& Schwarz M.P. 2017. 'Back to Africa': increased taxon sampling confirms a problematic Australia-to-Africa bee dispersal event in the Eocene. Systematic Entomology 42: 724-733. https://doi.org/10.1111/syen.12241

Kuhlmann M.2005. Diversity, distribution patterns and endemism of southern African bees (Hymenoptera: Apoidea). In: Huber B.A., Sinclair B.J. \& Lampe K.-H. (eds) African Biodiversity: Molecules, Organisms, Ecosystems: $167-172$. Proceedings of the $5^{\text {th }}$ International Symposium on Tropical Biology, Museum Koenig, Springer Verlag, Berlin.

Kuhlmann M. 2009. Patterns of diversity, endemism and distribution of bees (Insecta: Hymenoptera: Anthophila) in southern Africa. South African Journal of Botany 75: 726-738.

https://doi.org/10.1016/j.sajb.2009.06.016

Kuhlmann M. 2014. Revision of the "euryglossiform" species of the Afrotropical bee genus Scrapter Lepeletier \& Serville, 1828 (Hymenoptera: Apoidea: Colletidae). European Journal of Taxonomy 95: 1-69. https://doi.org/10.5852/ejt.2014.95

Kuhlmann M., Guo D., Veldtman R. \& Donaldson J. 2012. Consequences of warming up a hotspot: species range shifts within a centre of bee diversity. Diversity and Distributions 18: 885-897. https://doi.org/10.1111/j.1472-4642.2011.00877.x

Mayer C. \& Kuhlmann M. 2004. Synchrony of pollinators and plants in the winter rainfall area of South Africa - observations from a drought year. Transactions of the Royal Society of South Africa 59: 55-57. https://doi.org/10.1080/00359190409519162

Michener C.D. 2007. The Bees of the World. $2^{\text {nd }}$ Edition. The Johns Hopkins University Press, Baltimore. 
Manuscript received: 29 November 2019

Manuscript accepted: 11 February 2020

Published on: 18 May 2020

Topic editors: Gavin Broad and Nesrine Akkari

Desk editor: Kristiaan Hoedemakers

Printed versions of all papers are also deposited in the libraries of the institutes that are members of the EJT consortium: Muséum national d'histoire naturelle, Paris, France; Meise Botanic Garden, Belgium; Royal Museum for Central Africa, Tervuren, Belgium; Royal Belgian Institute of Natural Sciences, Brussels, Belgium; Natural History Museum of Denmark, Copenhagen, Denmark; Naturalis Biodiversity Center, Leiden, the Netherlands; Museo Nacional de Ciencias Naturales-CSIC, Madrid, Spain; Real Jardín Botánico de Madrid CSIC, Spain; Zoological Research Museum Alexander Koenig, Bonn, Germany; National Museum, Prague, Czech Republic. 